\title{
ANALYSIS OF UNRESOLVED COMPLEX MIXTURES OF HYDROCARBONS \\ EXTRACTED FROM LATE ARCHEAN SEDIMENTS BY COMPREHENSIVE TWO- DIMENSIONAL GAS CHROMATOGRAPHY (GC×GC)
}

Gregory T. Ventura, ${ }^{1}$ Fabien Kenig, ${ }^{1}$ Christopher M. Reddy ${ }^{2}$, Glenn S. Frysinger ${ }^{3}$, Robert K. Nelson $^{2}$, Ben Van Mooy ${ }^{2}$, and Richard B.Gaines ${ }^{3}$

${ }^{1}$ University of Illinois at Chicago, Department of Earth and Environmental Sciences, M/C 186, 845 West Taylor Street, Chicago, IL 60607-7059, USA

${ }^{2}$ Department of Marine Chemistry and Geochemistry, MS\#4, Woods Hole Oceanographic Institution, Woods Hole, MA 02543-1543, USA

${ }^{3}$ Department of Science, U.S. Coast Guard Academy, New London, CT 06320-8101, USA 


\begin{abstract}
Hydrocarbon mixtures too complex to resolve by traditional capillary gas chromatrography display gas chromatograms with dramatically rising baselines or "humps" of coeluting compounds that are termed unresolved complex mixtures (UCMs). Because the constituents of UCMs are not ordinarily identified, a large amount of geochemical information is never explored. Gas chromatograms of saturated/unsaturated hydrocarbons extracted from Late Archean argillites and greywackes of the southern Abitibi Province of Ontario, Canada contain UCMs with different appearances or "topologies" relating to the intensity and retention time of the compounds comprising the UCMs. These topologies appear to have some level of stratigraphic organization, such that samples collected at any stratigraphic formation collectively are dominated by UCMs that either elute early- (within a window of $\mathrm{C}_{15}-\mathrm{C}_{20}$ of $n$-alkanes), earlyto mid- $\left(\mathrm{C}_{15}-\mathrm{C}_{30}\right.$ of $n$-alkanes $)$, or have a broad UCM that extends through the entire retention time of the sample (from $\mathrm{C}_{15}-\mathrm{C}_{42}$ of $n$-alkanes). Comprehensive two-dimensional gas chromatography time-of-flight mass spectrometry $(\mathrm{GC} \times \mathrm{GC}-\mathrm{MS})$ was used to resolve the constituents forming these various UCMs. Early- to mid- eluting UCMs are dominated by configurational isomers of alkyl-substituted and non substituted polycyclic compounds that contain up to six rings. Late eluting UCMs are composed of $\mathrm{C}_{36}-\mathrm{C}_{40}$ mono-, bi-, and tricyclic archaeal isoprenoid diastereomers. Broad UCMs spanning the retention time of compound elution contain nearly the same compounds observed in the early-, mid-, and late retention time UCMs. Although the origin of the polycyclic compounds is unclear, the variations in the UCM topology appear to depend on the concentration of initial compound classes that have the
\end{abstract}


potential to become isomerized. Isomerization of these constituents may have resulted from hydrothermal alteration of organic matter.

\section{Introduction}

The identification of individual molecular constituents within complex organic mixtures of petroleum and sediment solvent extracts is typically achieved by a series of chemical and chromatographic separations. The most common technique employs a capillary gas chromatography (GC), often coupled to a mass spectrometer, in order to facilitate the separation, quantitation, and identification of individual molecular components in complex mixtures. Unfortunately, the chromatographic resolution afforded by capillary GC is insufficient to resolve some complex mixtures, which appear as a pronounced rising baseline or a series of rising baselines in a gas chromatogram (e.g. Gough and Rowland, 1990). In oils, the number of unidentified compounds comprising such unresolved complex mixtures (UCMs) may amount to 250,000 compounds (Sutton et al., 2005) indicating that an enormous amount of inaccessible, geochemical information is unexploited.

UCMs are frequently observed in petroleums and hydrocarbon (HC) extracts that have undergone biodegradation (Rowland and Maxwell, 1984; Killops and Al-Juboori, 1990; Gough and Rowland, 1990; Frysinger et al., 2003) or hydrothermal alteration (Rushdi and Simoneit 2002; Simoneit et al., 2004; Zárate-del Valle and Simoneit, 2005). UCMs of biodegraded oils typically contain a low abundance or complete absence, of aliphatic compounds (e.g. Connan, 1984; Rowland et al., 1986; Palmer, 1993; Swannell et al., 1995; Bost et al., 2001; Reddy et al., 2002). The removal of these constituents, which averages $32 \%$ of the total hydrocarbon 
composition of most crude oils (Killops and Killops, 2005) concentrates a preexisting complex mixture to yield the amplified chromatographic baseline of a UCM (Killops and Al-Juboori, 1990).

Petroleum formed by hydrothermal alteration of sedimentary organic matter undergo accelerated diagenesis and catagenesis (Simoneit and Lonsdale, 1982) from exposure to high temperature fluids that reach up to $350{ }^{\circ} \mathrm{C}$ (Simoneit, 1984, 1994; Simoneit et al., 1992; Kvenvolden and Simoneit, 1990). The UCMs of these hydrothermal petroleums contain abundant low and high molecular weight $n$-alkanes (e.g. Ogihara and Ishiwatari, 1998; Yamanaka et al., 2000; Rushdi and Simoneit, 2002a and b; Simoneit et al., 2004). These petroleums occasionally have homologous or pseudohomologous series of compounds with a carbon number predominance, such as $n$-cycloalkanes and branched alkanes with quaternary carbon atoms (BACQs; Ogihara and Ishiwatari, 1998; Simoneit, 1994; Rushdi and Simoneit, 2002a and b; Simoneit et al., 2004). TheUCMs of hydrothermal petroleums are thought to be composed of branched and cyclic compounds (e.g. Rushdi and Simoneit, 2002; Simoneit et al., 2004). Aside from this, their composition and formation has yet to receive the same level of attention as the UCMs produced by biodegradation. Because the compositional evolution of petroleum is strongly dependent on numerous variables such as temperature, time, source composition, water washing, fractionation during migration, and microbial degradation, the large inventory of organic compounds present in UCMs may yield critical information that can be used to understand factors regulating the occurrence of petroleum in subsurface environments.

Attempts to identify the constituents in UCMs have met with varying degrees of success and involved chemical oxidation (Gough and Rowland, 1990; Killops and Al-Juboori, 1990; Revill et al., 1992; Warton, 1999; Warton et al., 2000), thin layer chromatography (Liu et al., 
2005), chemical oxidation followed by treatment with molecular sieves (e.g. Armanios et al., 1994; Ellis et al., 1994; Fazeelat et al., 1994), statistical deconvolution methods (Pool et al., 1997; Dagan 2000; Demir et al., 2000) and field ionization mass spectrometry (Payzant et al., 1979). These attempts have led to the initial belief that UCMs were composed of hydrocarbons with similar chemical properties that include large numbers of branched and cyclic aliphatic and aromatic isomers (Eglinton et al., 1975; Payzant et al., 1979; Alexander et al., 1982; Sanders and Tibbetts, 1987; Killops and Al-Juboori, 1990). The use of oxidative degradation followed by GC enables the release of additional compounds, which led to the notion that UCMs might be mixtures of fairly simple compounds comprising unsubstituted alkyl chains such as isometric monoalkyl substituted "T"-branched alkanes (Gough et al., 1992; Warton et al., 2000). "T"branched alkanes were shown to be resistant to biodegradation (Gough et al., 1992). Warton et al. (1997) demonstrated that $3 \%$ of the alkanes from a biodegraded crude oil were "T" branched alkanes. Payzant et al. (1979) showed that UCM of the urea non adduct fractions of heavy oils was dominated by mono- and bicyclic compounds, with decreasing contribution of tri- to hexacyclic compounds. However, the structure of most of these compounds was not determined.

Even with excellent capillary GC columns and the extensive use of chemical degradation methods, some complex mixtures of compounds cannot be resolved and the nature of the compounds that form these UCMs remains unclear (Gough et al., 1992; Gough \& Rowland, 1990; Warton, 1999). This problem, which was latent in the study of biodegraded crude oil and crude oil contamination (i.e. Frysinger and Gaines, 2001; Reddy et al., 2002; Frysinger et al., 2003), is overcome with comprehensive two-dimensional gas chromatography $(\mathrm{GC} \times \mathrm{GC}$; Liu \& Phillips, 1991). GC $\times$ GC links two capillary columns, with different stationary phases, via a modulator that creates packets of analytes by temporarily focusing the effluent leaving the first 
column. The entrance of these packets into the secondary column produces a chromatogram with a high signal-to-noise ratio. Furthermore, the separation power of the primary column is conserved into the secondary column, such that compounds not resolved by the first column may be resolved by the second column. $\mathrm{GC} \times \mathrm{GC}$ was successfully used to separate and identify biomarkers (molecular fossils) in crude oils (Frysinger and Gaines, 2001), modern and Holocene marine sediment extracts (Johnson et al., 2003), and UCMs of crude oil contaminated sediments (Frysinger et al., 2003; Reddy et al., 2002). More recently, GC $\times \mathrm{GC}$ has been used to distinguish drilling mud contaminants from naturally occurring compounds in oils (Reddy et al., 2007).

Sediments from the 2.710-2.704 Ga Tisdale and 2.685 to 2.676 Ga Porcupine Assemblage (Ayer et al., 2002) of the Abitibi greenstone belt of Ontario, Canada were analyzed to assess the composition, origin, and preservation potential of organic matter from Late Archaean hydrothermal depositional environments (Ventura, 2006; Ventura et al., 2007). Bitumens were extracted from greywackes and argillites of the Tisdale Assemblage were collected from interflow sedimentary rocks deposited between tholeiitic basalts and tholeiitic dacites (Brisban, 1997). Bitumens were also extracted from distal margin turbidites of the overlying Porcupine Assemblage (Fig. 1; Rice et al., 1992). These sediments were subjected to post burial hydrothermal alteration (Brisban, 1997; Kerrich and Ludden, 2000) and lower greenschist metamorphism (Dimroth et al., 1983; Thompson, 2002).

The saturated and unsaturated hydrocarbon $(\mathrm{s} / \mathrm{u} \mathrm{HC})$ fractions of these bitumens were observed to contain pronounced UCMs (Fig. 1; Ventura, 2006; Ventura et al., 2007). These UCMs have different appearances or "topologies" relating to the intensity and retention time of the compounds comprising the UCMs. These topologies also appear to have some level of stratigraphic organization suggesting that the type of UCM topology likely dependents upon the 
specific nature of the initial source of organic matter as well as diagenetic, or catagenetic processes (Ventura et al., 2007). In this study $\mathrm{GC} \times \mathrm{GC}-\mathrm{MS}$ is used to identify the hydrocarbons that represent the dominant compounds forming the different UCM topologies. These results are then used to explore potential mechanisms of UCM formation.

\section{Samples and methods}

\subsection{Samples}

Samples were collected near Timmins, Ontario in an area named the Porcupine Gold Camp (PGC). Samples were selected to represent the pronounced UCM topology of each stratigraphic formation. The s/u HC fractions of solvent extracts from seven samples included two greywackes from the Vipond Formation, one argillite from the Krist Formation, and four argillites from the Hoyle Formation. A complete description of the geologic setting, bulk organic carbon characterization, and biomarker composition is provided in Ventura (2006) and Ventura et al. (2007).

\subsection{Methods}

\subsubsection{Bitumen extraction}


The surfaces of all samples were either scrubbed first with a wire brush and rinsed with double distilled water before being washed with dichloromethane (DCM)/methanol $(\mathrm{MeOH})$ in a $7.5: 1, \mathrm{v} / \mathrm{v}$ ratio or ground off using a steel wire brush attached to a Dremmel. The samples were then ground to a powder using a shatter box. Between 100 to $180 \mathrm{~g}$ of powdered sediment was Soxhlet extracted with a mixture of dichloromethane: methanol (DCM:MeOH; 7.5:1 v/v) for 72 hr. The resulting bitumen was then separated into polar and apolar fractions by column chromatography on alumina oxide following the method described in Simons and Kenig (2001). The apolar fraction was collected using hexane/DCM $(9: 1 \mathrm{v} / \mathrm{v})$ as an eluent. Polar fractions were recovered using DCM/MeOH $(1: 1 \mathrm{v} / \mathrm{v})$ as an eluent. Elemental sulfur was removed from the apolar fractions by passing the apolar fraction through a Pasteur pipette filled with activated $\mathrm{Cu}$ $(\mathrm{HCl} 6 \mathrm{~N})$ using hexane as the eluent. Apolar fractions were then separated into s/u $\mathrm{HC}$ and aromatic fractions by column chromatography on silica gel. S/u HC fractions were recovered with hexane. Aromatic fractions were recovered using DCM/MeOH $(7.5: 1 \mathrm{v} / \mathrm{v})$ as an eluent. Sub-fractions were rotary evaporated to $\sim 1 \mathrm{~mL}$ volume, transferred to tared vial, dried under a continuous low flow of $\mathrm{N}_{2}$, and again weighed. A procedural blank was added to each batch of samples.

\subsubsection{Gas Chromatography -Mass Spectroscopy (GC-MS)}

The s/u HC and aromatic fractions were analyzed in full scan and selected ion monitoring (SIM) modes using a Hewlett-Packard 6890 gas chromatograph (GC) coupled to a HewlettPackard 5973 mass selective detector (MSD). The GC was fitted with a HP-5MS capillary column (30-m; 0.25-mm ID; $0.25-\mu \mathrm{m}$ film thickness). The MSD was operated in electron ionization mode at $70 \mathrm{eV}$, scanning a mass range of $\mathrm{m} / \mathrm{z} 40-650$ at $2.44 \mathrm{scans} / \mathrm{sec}$. Injection was 
done in pulsed-splitless mode and helium was the carrier gas. Samples were injected at $60{ }^{\circ} \mathrm{C}$ (held for $1.5 \mathrm{~min}$.). The oven temperature was programmed to $130^{\circ} \mathrm{C}$ at $20^{\circ} \mathrm{C} \mathrm{min}^{-1}$, and then at $4{ }^{\circ} \mathrm{C}$ min. ${ }^{-1}$ to $315^{\circ} \mathrm{C}$, and held at $315^{\circ} \mathrm{C}$ for $90 \mathrm{~min}$.

\subsubsection{Metastable reaction monitoring gas chromatography-mass spectrometry (MRM-} GCMS)

Metastable reaction monitoring (MRM) was performed at the Department of Earth, Atmospheric and Planetary Sciences, Massachusetts Institute of Technology (Cambridge, MA, USA) following the method described in Brocks et al. (2003). Saturated and unsaturated fractions of 23 of the 26 samples were analyzed by GC-MS MRM using a VG Autospec UltimaQ coupled to a CarloErba GC (8000 series) with a tandem high resolution, double focusing magnetic sector-quadroupole mass analyzer. Internal standard $\mathrm{D}^{4}\left(\mathrm{~d}_{4}-\mathrm{C}_{29}-\alpha \alpha \alpha\right.$-ethylcholestane; Chiron Laboratories AS) was added to all samples prior to injection.

\subsubsection{Comprehensive two-dimensional gas chromatography -mass spectroscopy (GC×GC-} MS)

S/u HC fractions were analyzed by $\mathrm{GC} \times \mathrm{GC}-\mathrm{MS}$ using a Leco Pegasus 4D system consisting of a Hewlett-Packard 6890 GC configured with a split injector, two chromatography columns, a liquid nitrogen-cooled pulsed jet modulator, and a time-of-flight (TOF) mass spectrometer. Samples were dissolved in $25 \mu \mathrm{L}$ cyclohexane and $2.0 \mu \mathrm{L}$ was injected into a 300 ${ }^{\circ} \mathrm{C}$ splitless injector ( 2 min. purge time). The first-dimension separation was performed on a nonpolar 5\% phenyl polydimethylsiloxane phase (Agilent, DB-5, 30.0-m; 0.25-mm I.D.; 0.25-

$\mu \mathrm{m}$ film thickness) and temperature programmed from $120\left(1 \mathrm{~min}\right.$.) to $320^{\circ} \mathrm{C}$ at $2{ }^{\circ} \mathrm{C} \mathrm{min} .{ }^{-1}$. The 
modulation column was deactivated column (1.0-m x 0.10-mm I.D.) and temperature programmed from 200 ( $1 \mathrm{~min}$.) to $400{ }^{\circ} \mathrm{C}$ at $2{ }^{\circ} \mathrm{C} \mathrm{min} .^{-1}$. The second-dimension separation was performed on a polar 50\% phenyl equivalent polysiloxane phase (BPX-50, SGE, 1.5-m; 0.10mm I.D.; 0.1- $\mu \mathrm{m}$ film thickness) and temperature programmed from 120 (1 min.) to $320^{\circ} \mathrm{C}$ at 2 ${ }^{\circ} \mathrm{C}$ min. ${ }^{-1}$. A $1.0 \mathrm{~m}$ TOF detector transfer line of 0.10-mm I.D. deactivated column was used. Hydrogen was used as the carrier gas in constant flow mode $(1.2 \mathrm{~mL} / \mathrm{min})$. The $\mathrm{GC} \times \mathrm{GC}$ modulator period was $8 \mathrm{~s}$. The $\mathrm{GC} \times \mathrm{GC}$ was coupled with a Leco time of flight mass spectrometer that collected spectra from 45 to $600 \mathrm{u}$ at $100 \mathrm{~Hz}$. A detector voltage of $1800 \mathrm{~V}$ was used with a solvent delay of $11 \mathrm{~min}$. The similar column array used for GC $\times$ GC-FID provided equivalent compound separation.

Comparisons of retention times and mass spectral data collected by GC-mass spectrometry (GCMS), GC-MRM-MS, and GC $\times$ GC-MS biomarker compound classes were used to identify the presence of common biomarker compound classes such as $n$-alkanes, branched alkanes, acyclic isoprenoids, and polycyclic terpanes, such as hopanes and steranes (Ventura, 2007). $\mathrm{C}_{40}$ acyclic irregular isoprenoids were identified by mass spectral analysis using $\mathrm{GC} \times \mathrm{GC}$ MS and coinjection of an archaeal lipid standard containing acyclic, mono-, bi-, and tricyclic biphytane. Cycloalkanes were tentatively identified by mass spectral analysis. All reported mass spectra were obtained using the "Peak True" deconvolution algorithm of ChromaToF, the data processing tool of Leco's software package. The "Peak True" algorithm is based on an approach by Biller and Biemann (1974). "Peak True" mass spectra have greater fragmentation resolution of closely eluting peaks and represents a more consistent and tractable method than conventional caliper selected approaches. 


\subsubsection{Preparation of the archeael biphytane standard.}

A standard mixture of archaeal biphytanes was prepared from membrane phospholipids of the archaeon Thermoplasma acidophilum (Matreya L.L.C) using protocols adapted from Pease et al. (1992) and DeLong et al. (1998). To remove the glyco- and phospho-lipid headgroups, the membrane lipid was hydrolyzed in $1.25 \mathrm{M} \mathrm{HCl}$ in $\mathrm{MeOH}$ at $100{ }^{\circ} \mathrm{C}$ for two hours. The reaction was neutralized with $3 \mathrm{M} \mathrm{NaOH}$ and extracted three times with DCM. After drying over $\mathrm{NaSO}_{4}$, an aliquot of the resultant glycerol dialkyl glycerol tetraethers (GDGTs) was examined for purity using high pressure liquid chromatography-mass spectrometry (HPLC/MS) as described by Hopmans et al. (2000). To cleave the ether bonds of the of GDGTs, the extract was refluxed in concentrated HI for 4 hours at $100{ }^{\circ} \mathrm{C}$, extracted three times with hexane and dried via rotary evaporation. To reduce the resultant alkyl iodides to hydrocarbons, the extract was dissolved in $2 \mathrm{M} \mathrm{LiAlH}_{4}$ in THF and refluxed under $\mathrm{N}_{2}$ for $2 \mathrm{hr}$. at $70^{\circ} \mathrm{C}$. Ethyl acetate was added dropwise to quench excess $\mathrm{LiAlH}_{4}$, and then the reaction was extracted with three additional aliquots of ethyl acetate, which were then dried over $\mathrm{NaSO}_{4}$. The presence of biphytanes was confirmed by GC-MS and comparison with spectra of DeLong et al. (1998).

\section{Results}

All samples collected at the PGC have s/u HC fractions with UCMs that can be grouped in three categories based on chromatographic baseline topology (Fig. 1). Type I UCMs are raised baselines from early- to mid- retention times corresponding to the elution of $\mathrm{C}_{15}-\mathrm{C}_{25} n$-alkanes. Type II UCMs are dramatically rising baselines at late retention times that span the range of $\mathrm{C}_{30}$ 
to $\mathrm{C}_{42} n$-alkanes UCMs with a type III topology have a single massive UCM of early- to lateretention time $\left(n-\mathrm{C}_{15}\right.$ to $\left.n-\mathrm{C}_{42}\right)$.

UCM topologies vary stratigraphically and geographically (Fig. 1). The s/u HC fractions of the four samples collected from the Vipond Formation have a type III UCM topology. The two samples collected from the Gold Center Formation samples have a type II UCM topology, and the Krist Formation sample has a type I UCM topology. All ten Hoyle Formation samples collected away from areas of gold mineralization have s/u HC fractions with a type I UCM topology and all nine Hoyle Formation samples collected in areas of gold mineralization have both type I and II topologies.

GC-MS was unable to resolve the constituents forming the three UCM topologies. Averaged mass spectra across these UCMs display abundant mono- and bi-unsaturated fragment ions, such as $m / z 97$ and $\mathrm{m} / \mathrm{z} 95$ (Fig. 2). Due to the abundance of aliphatic compounds within the Type I topology the most intense fragment ion is $m / z 57$ (Fig. 2A). Mass chromatography of the fragment ions $\mathrm{m} / \mathrm{z} 97, \mathrm{~m} / \mathrm{z} 95$ and $\mathrm{m} / \mathrm{z} 93$ illustrates the close elution of compounds producing mono-, bi-, and tri-unsaturated fragment ions upon electron ionization in all UCMs (Fig. 2A-D). Hydrogenation of these samples does not affect the UCM topology, suggesting the UCMs are dominated by cyclic compounds.

\subsection{Composition of Type I UCMs}

Type I UCMs are operationally defined as having a raised "baseline" in the $n-C_{15}-n-C_{25}$ range (Fig. 1). The GC $\times$ GC-MS total ion current (TIC) chromatogram (Fig. 3A) displays some well resolved compounds (e.g. $n$-alkanes). However, the mass of cyclic compounds appears unresolved. Because compounds forming the type I UCM have similar fragmentation patterns, 
monitoring of typical mono- and bicyclic fragment ions (e.g. $\mathrm{m} / \mathrm{z} 69, \mathrm{~m} / \mathrm{z} 83, \mathrm{~m} / \mathrm{z} 97$, and $\mathrm{m} / \mathrm{z}$ 123) does little to resolve diversity of these compounds. Visualization of individual peaks within the UCM is greatly enhanced by sequentially monitoring mass chromatograms of molecular ions for compounds with different number of rings and different numbers of carbon atoms over the entire elution range of the $\operatorname{UCM}$ (Fig $3 \mathrm{~B}$ and $\mathrm{C}$ ). For example, for the $\mathrm{C}_{16}$ and $\mathrm{C}_{17}$ compounds, mass chromatography of $\mathrm{m} / \mathrm{z} 224$ and $\mathrm{m} / \mathrm{z} 238$ (monocyclic), $\mathrm{m} / \mathrm{z} 222$ and $\mathrm{m} / \mathrm{z}$ 236 (bicyclic), $\mathrm{m} / \mathrm{z} 220$ and $\mathrm{m} / \mathrm{z} 234$ (tricyclic), and $\mathrm{m} / \mathrm{z} 218$ and $\mathrm{m} / \mathrm{z} 232$ (tetracyclic) shows four sub-parallel lineament of peaks, and one peak for $m / z 218$ (tetracyclic; Fig. 3B and C). When this approach is applied to molecular ions of compounds from $\mathrm{C}_{15}$ to $\mathrm{C}_{29}$ (Fig. 3D) the bulk of the UCM is observed to consist of near uniformly distributed peaks of overlapping groups of mono- $\left(\mathrm{C}_{13}-\mathrm{C}_{29}\right)$, bi- $\left(\mathrm{C}_{15}-\mathrm{C}_{25}\right)$, tri- $\left(\mathrm{C}_{16}-\mathrm{C}_{25}\right)$, tetra- $\left(\mathrm{C}_{16}-\mathrm{C}_{23}\right)$, penta- $\left(\mathrm{C}_{19}-\mathrm{C}_{21}\right)$, and hexacyclic $\left(\mathrm{C}_{22}-\mathrm{C}_{23}\right)$ unsusbstituted and alkylsubstituted compounds (Fig. 3D). The tentative identification of some of these compounds is provided below.

\subsubsection{Monocyclic alkanes}

The overall distribution of monocyclic alkanes is monitored by the summed mass chromatography of fragment ions $\mathrm{m} / \mathrm{z}$ 96, and $\mathrm{m} / \mathrm{z} 110$ (Fig. 4A). However, to resolve the distribution of monocyclic alkanes at each carbon number, the mass chromatogram of the molecular ion was added to the summed mass chromatogram. For example, monitoring of $\mathrm{C}_{16}$ alkylcycloalkanes was done on the summed chromatogram $m / z 224+m / z 96+m / z 110$ (Fig. 4B).

$n$-Alkylcyclohexane and $n$-alkylcyclopentane were identified on the basis of mass spectral fragmentation and by comparison with published spectra (e.g. Rubinstein and Strausz, 
1979; Hoffmann et al. 1987; Simoneit et al. 2004). n-Alkylcyclopentane and nalkylcyclohexane homologues having 16 or less carbon atoms nearly coelute (Fig. 4B). Homologues with greater than 16 carbon atoms become increasingly separated in the first dimension (Fig. 4A). Tentatively identified $n$-alkylcycloheptane (Fig. 5A) elutes at slightly earlier first dimension and later second dimension retention times relative to $n$-alkylcylohexane and $n$-alkylcyclopentane (Fig. 4A and B). The $n$-alkylcyclohexanes, $n$-alkylcyclopentanes, and n-alkylcycloheptanes of the Vipond and Krist Formation sediment extracts have extremely pronounced carbon number predominance. Such carbon number preference is inconsistent with the age and maturity of these sediments and is likely a product of more recent contamination (Grosjean and Logan, 2007). A similar carbon number predominance is not observed in the substituted cycloalkanes contributing to the formation of type I UCM.

A group of 7 peaks, tentatively identified as isomers of nonylmethylcyclohexane (Fig. 4B), were identified by mass spectral comparison and by the similarity of the first dimension isomers elution pattern to published data (Fowler et al., 1986; Hoffmann et al., 1987). The mass spectra of trans 1-methyl-2-nonylcyclohexane is shown in Figure 5B. The mass spectra of all observed alkylmethylcyclohexane stereoisomers were nearly identical and dominated by the fragment ion $\mathrm{m} / \mathrm{z}$ 97. Alkylmethylcyclohexanes were observed in the $\mathrm{C}_{16}-\mathrm{C}_{28}$ range, which extends past the zone of maximum intensity of the UCM.

Three groups of monocyclic compounds eluting at slightly earlier first and second dimension times to the cluster of alkylmethylcyclohexanes (Fig. 4A and B) are also present. The peaks in each group contain identical fragmentation patterns suggesting the members of each group have stereochemical differences similar to the alkylmethylcyclohexanes. However, slight difference in the fragmentation patterns between each group indicates a variation in the number 
of alkyl-substituents bonded to the cyclohexane or cyclopentane ring. The first group containing three peaks that elute before the alkylmethylcyclohexanes is tentatively identified as isomers of alkylmethylcyclopentanes (Fig. 5). The mass spectra of these peaks display a pattern of skeletal ring decomposition which results in the formation of 1-alkene ions (McLafferty and Tureček, 1993) that is common to cycloalkanes with less than six-membered rings. The dominant $\mathrm{m} / \mathrm{z} 83$ fragment ion, characteristic of a 6 carbon ring, is likely due to the presence of a methyl substituent on the pentacyclic ring. The two other groups noted Unknown $X_{1}$ and $X_{2}$ in Figure 4B could not be tentatively identified on the sole basis of their mass spectral fragmentation (Fig. $5 \mathrm{E}$ and F), but are likely compounds with two or more methyl substituents on a cyclohexane or cyclopentane ring.

\subsubsection{Bicyclic alkanes}

Bicyclic alkanes above $\mathrm{C}_{18}$ occupy part of the same $\mathrm{GC} \times \mathrm{GC}$ chromatographic space as monocyclic alkanes that have one less carbon atom (Fig. 3D). Monitoring of bicyclic alkane distributions is thus facilitated by mass chromatography of molecular ions. In the mass chromatogram of the molecular ion of $\mathrm{C}_{16}$ bicyclic alkanes $(\mathrm{m} / \mathrm{z} 222$; Fig. $6 \mathrm{~A})$, three groups of peaks with very similar mass spectra are identified.

The first group (B in Fig. 6A) includes at least four peaks. The mass spectra of these compounds (Fig. 6B) include the fragment ion $\mathrm{m} / \mathrm{z}$ 137, which corresponds to a cleaved $\mathrm{C}_{10}$ bicyclic ion (decalin) from the $\mathrm{C}_{6}$ alkyl substituent of the molecular ion $(\mathrm{m} / \mathrm{z} 220)$. The presence of a smaller fragment ion $\mathrm{m} / \mathrm{z} 136$ indicates a hydrogen rearrangement, formed when an alkyl substituent is lost via the cleavage of the C-C bond $\alpha$ to the ring system. The base peak $\mathrm{m} / \mathrm{z} 81$ is formed by the cleavage of the cyclohexane rings of the decalin ion $\alpha$ to the two tertiary carbon 
atoms of the bicyclic system (e.g. Golovkina et al., 1984). Thus, it can be hypothesized that the compounds forming the first group are isomers of hexyldecalins. However, the position of the alkyl substituent ( 1 or 2 ) cannot be determined and it is possible that both isomers are present.

The second group (C in Fig. 6A), includes four peaks with nearly identical mass spectra that are tentatively identified as alkyl-methyldecalins (Fig. 6C). Cleavage of a $\mathrm{C}_{5}$ alkyl substituent from the molecular ion results in the formation of a $\mathrm{C}_{11}$ bicyclic ion represented by the fragment ion $\mathrm{m} / \mathrm{z} 151$. The base peak $\mathrm{m} / \mathrm{z} 95$ indicates fragmentation $\alpha$ to the tertiary carbon atoms of the methyl substituted cyclohexyl-ring. The position of both methyl and pentyl substituents cannot be determined on the sole basis of the mass spectral data.

The third group (D) includes three peaks with nearly identical mass spectra (Fig. 6 A). The mass spectra of these compounds have an $\mathrm{m} / \mathrm{z} 81$ base peak likely formed by the cleavage of a cyclohexane ring from a bicyclic system. However, the mass spectral data is unspecific and no structure can be proposed at this point.

\subsubsection{Tricyclic compounds}

Tricyclic compounds volumetrically contribute less to the type I UCMs than monocyclic and bicyclic compounds. Five groups of compounds are identified on the mass chromatogram of the molecular ion ( $\mathrm{m} / \mathrm{z} 220)$ of $\mathrm{C}_{16}$ tricyclic alkanes (Fig. 7A). All of the peaks within each group have nearly identical mass spectra. The mass spectra of these compounds (Fig. 7) do not match those of tricyclic terpanes (e.g. they do not have a fragment ion $\mathrm{m} / \mathrm{z} 123$ ). Interpretation of the mass spectrometric data was facilitated by Kiselev's et al. (1984) study of perhydrophenanthrene and perhydroanthracene fragmentation. The mass spectrum of peak E (Fig. 7E) has a fragment ion $\mathrm{M}^{+}-29(\mathrm{~m} / \mathrm{z} 191)$ of intensity equal to that of the molecular ion, 
suggesting the loss of an ethyl substituent from one of the terminal rings of the perhydroanthracene or perhydrophenantrene. Otherwise, the mass spectrum of peak E is similar to those published by Kiselev et al. (1984). Detail of the fragmentation pattern is shown in figure 7E. The fragment ion $\mathrm{m} / \mathrm{z} 150$ corresponds to a perhydro-cyclopropa[a]naphthalene. Thus, peak E is tentatively identified as an ethyl-perhydroanthracene or ethyl-perhydrophenanthrene, though the location of the ethyl substituent remains unclear.

The compounds of the first group (B) of Fig. 7A are tentatively identified as isomers of dimethyl-substituted perhydroanthracene or perhydrophenanthrene on the basis of mass spectral data (Fig. 7B). The fragment ions $\mathrm{M}^{+}-15$ and $\mathrm{M}^{+}-29$ correspond to the loss of one and two methyl substituents, respectively. The fragment ions $\mathrm{m} / \mathrm{z} 149$ and $\mathrm{m} / \mathrm{z} 164$ correspond to an octahydro-methylnaphathalene and perhydro-cyclopropa[a]naphthalene, respectively. The position of the methyl substituents, located on terminal rings, could not be determined. The group of peak C and peak D (Fig. 7A) are tentatively interpreted to be mono- or bi-substituted dodecahydrofluorene (Fig. 7C, and D) on the basis of mass spectral fragmentation. No tentative structure for the group of peak $\mathrm{F}$ is proposed.

\subsubsection{Tetracyclic alkanes}

Tetracyclic alkanes are also part of the type I UCM (Fig. 8). The mass chromatogram of the molecular ion of $\mathrm{C}_{16}$ tetracyclic compounds $(\mathrm{m} / \mathrm{z} 218)$ displays one peak, tentatively identified as hexadecahydropyrene by comparison of its mass spectra with that of published reports (McLafferty et al., 1989). The mass chromatogram for the $\mathrm{m} / \mathrm{z} 232$ molecular ion of $\mathrm{C}_{17}$ tetracyclic compounds displays 5 major peaks (Fig. 8A). Peak B, C, and D are tentatively identified as methyl-hexadecahydro-pyrenes on the basis of mass spectral fragmentation patterns 
(Fig. 8B, $\mathrm{C}$ and $\mathrm{D})$. These peaks all have $\mathrm{M}^{+}-15$ fragment ions $(\mathrm{m} / \mathrm{z} 217)$ suggesting the presence of a methyl substituent. For peak B and C, methyl substitution at C-1 or C-2 favors cleavage of the $\mathrm{C}_{4} \mathrm{H}_{8}$ (isobutylene) or $\mathrm{C}_{4} \mathrm{H}_{10}$ (isobutyl) from the molecular ion, resulting in the fragment ions $\mathrm{m} / \mathrm{z} 175$ and $\mathrm{m} / \mathrm{z}$ 177, respectively (Fig. 8B and C). The fragment ions $\mathrm{m} / \mathrm{z} 189$ and $\mathrm{m} / \mathrm{z} 191$ are formed by cleavage of the $\mathrm{C}_{3} \mathrm{H}_{8}$ or $\mathrm{C}_{3} \mathrm{H}_{6}$ (propylene) from the ring opposed to that carrying the methyl substituent. Thus, peaks B and C are tentatively interpreted to be 1- or 2-methylhexadecahydro-pyrenes. For peak D, methyl substitution at C-4 explains the absence of the fragment ions $\mathrm{m} / \mathrm{z} 175$ and $\mathrm{m} / \mathrm{z} 177$ (no possible cleavage of $\mathrm{C}_{4}$ units) and the presences of the fragment ions $m / z 189$ and $m / z$ 191, via cleavage of a $\mathrm{C}_{3} \mathrm{H}_{8}$ or $\mathrm{C}_{3} \mathrm{H}_{6}$ unit from the molecular ion (Fig. 8D). Thus peak D is tentatively identified as a 4-methyl-hexadecahydro-pyrene. The mass spectral fragmentation for peak E (Fig. 8E) cannot be rationalized and no tentative structure is proposed.

There is no fragment ion $\mathrm{M}^{+}-15$ in the mass spectrum of peak F (Fig. 8F), suggesting that this compound is not methyl substituted. Thus, considering the abundance of the fragment ions $\mathrm{m} / \mathrm{z} 175$ and $\mathrm{m} / \mathrm{z}$ 191, we tentatively identified peak F as hexadecahydro-benzo[de]anthracene, the only structure possible.

\subsubsection{Pentacyclic alkanes}

Pentacyclic alkanes were tentatively identified in the type I UCM where they are in low abundance compared to mono-. bi-, tri-, and tetracyclic alkanes. The distribution of $\mathrm{C}_{19}$ and $\mathrm{C}_{20}$ pentacyclic compounds is monitored on the summed mass chromatogram $\mathrm{m} / \mathrm{z} 258+\mathrm{m} / \mathrm{z} 272$ (Fig. 9A). Peaks B, C, and D are $\mathrm{C}_{19}$ compounds $\left(\mathrm{M}^{+}\right.$258). Peaks E, F, G, and $\mathrm{H}$ are $\mathrm{C}_{20}$ compounds $\left(\mathrm{M}^{+} 272\right)$. 
Octadecahydro-benzo[cd]pyrene is the only possible structural isomer for an hexacyclic compound comprised solely of 6-membered rings having a mass of $258 \mathrm{amu}$ (Fig. 9B). The mass spectrum of peak B (Fig. 9B) contains the fragment ions $m / z 217\left(\mathrm{M}^{+}-41\right)$ and $\mathrm{m} / \mathrm{z} 215\left(\mathrm{M}^{+}\right.$43). These fragment ions correspond to tetradecahydropyrene and dodecahydropyrene ions formed by cleavage of propylene and propane, respectively, from the fragment ion $\left(\mathrm{M}^{+}-258\right)$. Fragment ions $\mathrm{m} / \mathrm{z} 173$ and $\mathrm{m} / \mathrm{z} 175$ correspond to octahydrophenalene and decahydrophenalene ions formed by cleavage of saturated and unsaturated $\mathrm{C}_{3}$ units from dodecahydropyrene ions. Thus, on the basis of mass spectral data, peak B is tentatively interpreted as octadecahydrobenzo[cd]pyrene.

Peak C and D must be pentacyclic compounds with at least one cyclopentane ring. The mass spectrum of peak $\mathrm{C}$ is weak and difficult to interpret and most probably includes fragment ions derived from more than one compound. However, the very high intensity of fragment ion $\mathrm{m} / \mathrm{z} 215\left(\mathrm{M}^{+}-43 ; 100 \%\right)$ suggests presence of a methyl substituent on the pentacyclic ring and cleavage of the bond between the two adjacent tertiary carbon atoms (Fig. 9C). Thus, very tentatively, peak $\mathrm{C}$ may be octadecahydro-methylcyclopenta[cd]pyrene. The mass spectra of peak D does not display an $\mathrm{M}^{+}-15$ fragment ion (Fig. 9D). The abundance of the fragment ion $\mathrm{m} / \mathrm{z} 173$, corresponding to an octahydrophenalene ion, suggests the cleavage of two rings and loss of two $\mathrm{C}_{3}$ units. Thus, an octadedahydro-cyclopenta[e]pyrene structure is proposed for peak D.

Peaks $\mathrm{E}$ and $\mathrm{F}$, both $\mathrm{C}_{20}$ pentacyclic hydrocarbons, have very similar mass spectra (Fig. 9E and F). The fragment ion $\mathrm{m} / \mathrm{z} 257\left(\mathrm{M}^{+}-15\right)$ suggests the presence of a methyl substituent on the pentacyclic ring system. The tetradecahydro-pyrene ion $(\mathrm{m} / \mathrm{z} 215)$ indicate the cleavage of a $\mathrm{C}_{4}$ unit, suggesting that the methyl substituent is located in position 3,4 or 5 of an 
octadecahydro-benzo[cd]pyrene. Thus, peak E and F are tentatively identified as octadecahydromethylbenzo[cd]pyrene isomers.

Peak $\mathrm{G}$ and $\mathrm{H}$ are both $\mathrm{C}_{20}$ pentacyclic hydrocarbon. The mass spectra of both these peaks do not display an $\mathrm{M}+-15$ fragment ion. The mass spectral fragmentation patterns for these compounds are typical of a condensed ring system but are not informative enough to hypothesize a structure.

\subsubsection{Hexacyclic alkanes}

Hexacyclic alkanes were also detected in type I UCM. Mass chromatography of the molecular ion for $\mathrm{C}_{22}$ hexacyclic compounds ( $\mathrm{m} / \mathrm{z} 298$; Fig. 10A) has three peaks with mass spectra including $\mathrm{m} / \mathrm{z} 298$ as a molecular ion. All these mass spectra include the fragment ion $\mathrm{m} / \mathrm{z} 257\left(\mathrm{M}^{+}-41\right)$ corresponding to the typical loss of a propylene fragment from a condensed ring system, as observed for tetracyclic and pentacyclic alkanes. None of the spectra display fragment ions with $m / z \mathrm{M}^{+}-15$ nor $\mathrm{M}^{+}-29$ (Fig. 10B) suggesting that these compounds are not methyl substituted and, thus, do not include five membered rings.

Only three structural isomers are possible for hexacyclic $\mathrm{C}_{22}$ compounds made of cyclohexane rings having a mass $298 \mathrm{amu}$ : Icosahydro-dibenzo[cd,mn]pyrene, icosahydrodibenzo[def,mno]chrysene, and docosahydro-benzo[ghi]perylene (Fig. 10C). However, it is not possible to determine which of these three structures corresponds to each peak in the mass chromatogram $\mathrm{m} / \mathrm{z} 298$, the mass spectral data for peaks C and $\mathrm{D}$ (not shown) being too weak.

\subsection{Composition of Type II UCMs}


$\mathrm{GC} \times \mathrm{GC}-\mathrm{MS}$ enables identification of compounds forming the bulk of the type II UCM. These UCMs are composed of acyclic and cyclic terpenoids with 1 to 5 rings, which form bands separated in the second dimension of the $\mathrm{GC} \times \mathrm{GC}$ chromatogram (Fig. 11). Each band is composed of one or more series of compounds. For example, the tetracyclic band include both steroids and secohopanes, which elute in the second dimension after a pseudohomologous series of tricyclic terpanes (cheilathanes) and before a later eluting band pentacyclic triterpanes (hopanoids; Fig. 11).

The dominant compounds forming the type II UCMs are $\mathrm{C}_{36}-\mathrm{C}_{41}$ acyclic, mono-, bi- and tricyclic irregular (head-to-head) isoprenoids. Acyclic 3,7,11,15,18,22,26,30octamethyldotriacontane $\left(\mathrm{C}_{40} \mathrm{H}_{82}\right.$; biphytane $)$ and $\mathrm{C}_{40}$ mono-, bi- and tricyclic cyclic archaeal lipids were identified on the basis of mass spectral fragmentation and coelution with an archaeal lipid standard (Fig. 12). Lower carbon number derivatives of the acyclic and cyclic biphytanes were identified on the basis of mass spectral data, following the rational of the fragmentation of acylic and cyclic biphytane (Fig.12 and 13). GC $\times$ GC-MS analysis of sample OC-114m enabled the resolution of additional acyclic irregular isoprenoid with more than 40 carbon atoms (Fig. 11 and 12). No cyclic isoprenoids with more than 40 carbons were detected and neither tetracyclic biphytane nor derivatives of tetracyclic biphytanes were observed. The $\mathrm{C}_{40}$ mono, bi-, and tricyclic biphytane derivatives and their lower $\mathrm{C}_{36}-\mathrm{C}_{39}$ homologs are each, respectively, represented by doublets, triplets, and at least quadruplets of peaks with exactly the same mass spectra (Fig. 10). Within each group, the peaks are clearly separated in the $1^{\text {st }}$ dimension, but have nearly the same $2^{\text {nd }}$ dimension retention time, suggesting differences in volatility but similar polarity. 


\subsection{Composition of type III UCMs}

The s/u HC fraction of all samples collected from the Vipond Formation have a type III UCM topology. GC $\times$ GC-MS showed that type III UCMs are made of nearly the same compounds as those observed for type I and II UCMs. GC $\times \mathrm{GC}$ chromatograms are dominated by overlapping bands of alkyl-substituted mono-, bi-, and tri-cyclic compounds at early to midretention times. Although tetracyclic alkanes were not detected, minor contributions of pentaand hexacyclic compounds were also present. The compounds forming the mass of the late eluting part of the UCM are dominated by hopanoids, steroids, tricycic terpanes, secohopanes, and acyclic, mono-, bi- and tricyclic irregular isoprenoids (archaeal lipids) with carbon number ranges similar to those observed for compounds forming the type II UCM. Thus, the massive type III UCM appears to be a hybrid of type I and II UCMs.

\section{Discussion}

\subsection{Origin of PGC UCMs}

The UCMs observed in the PGC samples are unlikely to have arisen by selective preservation of bioresistant compounds during biodegradation as ascribed to UCMs of biodegraded oils (e.g. Killops and Al-Juboori, 1990). Easily biodegradable, low molecular weight (LMW) n-alkanes and LMW acyclic isoprenoids, such as 2,6,10-trimethyltridecane or 2,6,10-trimethylpentadecane (Peters and Moldowan, 1993), are abundant in all samples. This is concordant with the observed low concentrations of biodegraded C-25 norhopanes (Ventura, 2006). Furthermore, biodegradation can explain neither the presence of highly isomerized 
archaeal lipids observed in the type II UCMs, nor the abundance of mono-, bi-, tri-, tetra-, pentaand hexacyclic alkanes in type I UCMs.

\subsubsection{Origin of type I UCMs}

The type I UCM forming compounds are not likely contributions from laboratory or field related contamination. Most of these compounds do not have a carbon number preference. Exceptions are $n$-alkylcyclopentanes, $n$-alkylcyclohexanes, $n$-alkylcycloheptanes of samples from the Vipond and Krist Formation, which have concentrations that are positively correlated with BAQCs. These compounds likely reflect contamination by products of commercial polyethylene products (Grosjean and Logan, 2007; Brocks et al., 2008). Monocyclic alkanes are devoid of a carbon number preference in samples that do not contain BAQCs (Ventura et al., 2007). The type I UCM forming compounds are also present in samples that had the surface of the core ground away prior to extraction (Ventura et al., 2007) and thus are unlikely to derive from surface contamination of the sample. It is unclear, however, whether these compounds share a common origin with one another or with those forming type II UCMs.

Very little information is currently available about the occurrence or formation of the tentatively identified cyclic compounds. Payzant et al. $(1979,1980)$ showed that the UCMs of extractable hydrocarbon of the Mannville oils, Lloydminster heavy oil, Cold Lake Bitumen, Athabasca bitumen, and Athabasca asphaltene pyrolysate are dominated by mono- to hexacyclic hydrocarbons and identified the dominant compounds as substituted and unsubstituted monocyclic hydrocarbon and decalin, as is observed in the type I UCMs. Payzant et al. (1980) proposed that the tricyclic component of the UCM of Cold Lake bitumen is composed of alkyl 
perhydrophenanthrenes. No structure was proposed for the tetracyclic, pentacyclic and hexacyclic component of the UCMs of Manville oils (Payzant et al., 1980).

If the compounds forming type I UCM share a common origin, several hypothetical scenarios may explain their formation. These compounds appear unrelated to cyclic terpenoids and are not known biosynthetic products. Their presence may thus represent hydrogenation of polycyclic aromatic hydrocarbons (PAHs). Although many reductive techniques are known, they typically involve support from noble metal catalysis under high hydrogen pressure and/or elevated temperatures, either in the gas phase or in the presence of organic solvents (Nelkenbaum et al., 2007). Saturation typically leads to the formation of additional isomers as observed by Yuan and Marshall (2005) who used a mixture of supercritical $\mathrm{CO}_{2}$ with molecular hydrogen to form six tetradecahydroantracene isomers from the reduction of anthracene.

Alternatively, anaerobic degradation of PAHs has been demonstrated to yield hydrogenated derivatives of PAHs (Annweiler et al., 2002; Mechenstock et al., 2004). Denitrification and sulfate reducing conditions can lead to the transformation of naphthalene and phenanthrene to naphthoic and phenanthroic acids (Mechenstock et al., 2004). Aitken et al. (2004) proposed a reductive pathway involving carboxylation of naphthalene to 2-naphthoic acid, followed by several hydrogenation steps, which may account for the presence of decahydro-2-nahthtoic acid in many biodegraded oils. Additional steps to the reductive 2naphthoic acid pathway include cleavage of a $\mathrm{C} 2$-fragment via beta-oxidation with another metabolite to yield carboxycyclohexylacetic acid (Mechenstock et al., 2004). Alkylation following decarboxylation of the decahydro-2-nahthtoic and carboxycyclohexylacetic acid could potentially yield alkyldecalins and alkylcyclohexanes, respectively. However, little is known 
about the biodegradability of higher PAH ring systems and as stated above, the PGC extracts display little evidence of biodegradation.

Lastly, Rubinstein and Strausz (1979) have proposed that alylcyclohexane and alkylmethylcyclohexane series of South Western Alberta oils were formed by the cyclization of fatty acids during diagenesis. This hypothesis was endorsed by Payzant et al. (1980) to explain the cyclohexane, decalin, and the perhydrophenanthrene series tentatively identified in Cold Lake bitumen. If such a process is viable for monocyclic and bicyclic alkanes, it appears increasingly unlikely to account for the formation of compounds with more than three rings. However, all but one of the tentative structures proposed here for the tetracyclic, pentacyclic and hexacyclic compounds of type I UCM can be formed from cyclization of a single aliphatic branched compound.

\subsubsection{Origin of type II UCMs}

Type II UCMs are dominated by acyclic and cyclic irregular head-to-head isoprenoids considered biomarkers of archaea (e.g. Chappe et al., 1979 a and b, 1982; Brassell et al., 1981; Petrov et al., 1990; Vink et al., 1998; Stefanova, 2000). Biphytane and cyclized derivatives of biphytane are the hydrocarbon skeletons formed by cleavage of GDGTs derived from archaea (e.g. Chappe et al., 1982; Volkman and Maxell, 1986; Kates, 1997). Archaeal lipid contributions are highly variable in samples from the Hoyle Formation of the Porcupine Assemblage. Archaeal lipids were not observed in the Krist Formation of the Porcupine Group. Hoyle Formation core samples OC-114m and HP12378GZ collected from the Owl Creek and Hoyle Pond Mines, respectively, display dramatically higher relative abundance of acyclic and cyclic biphytane, as well as biphytane derivatives, than the samples collected away from gold 
producing centers and likely represent Late Archaean, secondary additions of organic matter from subsurface hydrothermal communities (Ventura et al., 2007).

Thermophilic and methanogenic Euryarchaeota synthesize GDGTs with acyclic biphytane (e.g. caldarchaeol) as well as biphytane with up to 4 pentacyclic rings (De Rosa et al. 1988; Sprott et al., 1997; Schouten et al., 1998; Schouten et al., 2000). The relative abundance of acyclic and cyclic archaeal lipids was calculated by integrating peak areas of the GC $\times$ GC TIC chromatogram. The percentage of acyclic archaeal lipids in sample OC- $114 \mathrm{~m}$ is $30 \%$, the percentage of mono-, bi-, and tricyclic archaeal lipids was 27,23 , and $20 \%$, respectively. The high relative abundance of cyclic compounds ( $70 \%$ ) relative to the acyclic compounds $(30 \%)$ is consistent with hyperthermophillic archaea (Ernst et al., 1998; Uda et al., 2001; De Rosa et al., 1980). The presence of $>\mathrm{C}_{40}$ acyclic isoprenoids may indicate derivatives of H-type Caldarchaeols having $\mathrm{C}_{80}$-isoprenoid carbon chains that derive from the hyperthermophilic methogen Methanothermus fervidus (Morri et al., 1998). However, the existence of these molecules has been recently refuted (Gattinger et al., 2002).

\subsubsection{Thermal stress of type II UCM constituents}

The archaeal lipids contributing to the type II and III UCM topologies have undergone substantial thermal stress resulting in the production of archaeal lipid derivatives. The distribution of archaeal lipid derivatives is consistent with a non-random pattern of cracking. The mass chromatograms of the fragment ions $\mathrm{m} / \mathrm{z} 194$ and $\mathrm{m} / \mathrm{z} 165$, which correspond to the fragmentation of cyclic archaeal lipids, do not display compounds with less than 30 carbon atoms (Fig. 12 and 13). The absence of archaeal lipid derivatives formed by cleavage of a carbon-carbon bond at the mid-section of the isoprenoid skeleton strongly suggests that 
hydrocarbon cracking preferentially affects the terminal ends of the isoprenoids. Subsequently, the lower carbon number biphytane derivatives $\left(<\mathrm{C}_{39}\right)$ likely formed by several episodes of successive cracking of the terminal carbon atoms of biphytane and biphytane derivatives. This cracking pattern may be due, in part, to the higher thermal resistance of carbon-carbon bonds with one tertiary substituted atoms relative to that of a carbon-carbon bonds (e.g. Fierro et al., 2002) as well as lower C-C bond strengths for carbon atoms located at the terminal ends of $n$ alkanes (e.g. Morrison and Boyd, 1973).

\subsubsection{Isomerization of type II UCM constituents}

The $\mathrm{C}_{40}$ mono, bi-, and tricyclic biphytane derivatives and their lower $\mathrm{C}_{36}-\mathrm{C}_{39}$ homologs are each, respectively, represented by doublets, triplets, and at least quadruplets of peaks with exactly the same mass spectra (Fig. 10). The elution pattern and number of peaks suggests that they correspond to diastereomers formed by isomerization, most probably, at the alkylsubstituted chiral carbon of pentacyclic rings. Stereoisomers formed by changes in the stereochemistry of methyl substituents are not separated by the non-chiral chromatographic column used here. Biogenic cyclic biphytanes have a specific stereochemical configuration, which is trans for the 1,3 substitution pattern of cyclopentane rings (Sinninghe Damsté et al., 2002; Montenegro et al., 2003). The PGC sample monocyclic biphytanes may have both a cis and trans ring conformation, resulting in two distinct peaks. Trans-trans, cis-trans, and cis-cis are the three possible conformations the rings in bicyclic biphytane and may explain the triplets of peaks with identical mass spectra observed. Up to 8 different stereochemical ring conformations are possible for tricyclic biphytanes. It is can be hypothesized that some of these tricyclic diastereomers coelute, resulting in the quadruplets of peaks observed. 
Nothing is known about the conditions required for the formation of diastereomers of cyclic archaeal isoprenoids. Diasteromers are commonly observed in geologic samples and are the products from either acid-clay catalyzed reactions and/or thermal stress (Rubinstien et al., 1975). However, acid-clay catalyzed reactions are unlikely to have resulted in the formation the PGC archaeal lipid diastereomers. The Hoyle and Owl Creek mines were hydrothermally active (Phillips, 1986; Roberts, 1987; Kerrich et al., 1987, Veizer, 1989, Brisban, 1997; Kerrich and Ludden, 2000). Illite, which later altered to mica and albite during greenschist metamorphism (Davies and Whitehead, 1993) is a weak Bronsted and Lewis acid (Tannenbaum et al., 1986) and its catalyzing activity is suppressed in the presence of water (Goldstein, 1983; Tannenbaum and Kaplan, 1985; Seewald, 2003). Catalytic activity of clay involves carbonium-ion intermediaries that generate a predominance of branched products (Seewald, 2003), which is inconsistent with dominance of cyclic moieties in the PGC sample solvent-extracts.

Isomerization of a chiral ring center is less common due to the steric hindrance imposed by the ring. High temperatures associated with catagenesis causes the covalent bond between hydrogen and a tertiary substituted chiral carbon to undergo bond elongation, which if broken produces a hydrogen radical $(\mathrm{H})$ or hydride ion $(\mathrm{H}-)$. Under such conditions, the broken bond may reform with equal probability that the same steric configuration is preserved or changed. Such transformations are favored at high temperatures and potentially require additions of metal catalysts (Akhmedov et al., 1999), or the presence of high hydrogen pressure to increase the likelihood of isomerization without excessive hydrocarbon cracking (Seewald, 1994). These conditions are thought to be common in hydrothermal environments in which $\mathrm{H}_{2} \mathrm{O}$ disproportionates forming $\mathrm{H}^{+}$and $\mathrm{OH}^{-}$buffered solutions (Rullkötter et al., 1984; Seewald, 1994, 2003; Lewan, 1997; Price and DeWitt, 2001). It is noteworthy, that within the PGC, exogenous 
hydrogen may have formed by serpentinization of mafic and ultramafic rocks located lower in the stratigraphic profile (Fyon et al., 1983).

\section{Conclusions}

The questions driving Precambrian organic geochemistry not only includes what constitutes syngeneity and to what end can syngeneity be established, but also to what range of depositional environments and physical and chemical burial conditions is sedimentary organic matter preserved. The accelerated crustal development of Earth's early history likely resulted in hydrothermal processes being common features of Archean depositional environments. Understanding how the composition and preservation of organic matter is affected by these

processes can help determine the diversity of geological localities that can yield extractable hydrocarbons.

This study analyzed bitumens extracted from hydrothermally altered late Achaean sediments. The s/u HC fractions of these bitumens contain three different UCM topologies, which were irresolvable by traditional GC-MS. The increased separation power of GC $\times$ GC-MS facilitated the tentative identification of multiple compound classes that were embedded within these UCMs. Type I UCMs are composed of mono- to hexacycloalkanes of unknown origin. Type II UCMs are mostly composed of $\mathrm{C}_{35}-\mathrm{C}_{40}$ archaeal lipids. Type III UCMs represent a mix of Type I and II UCM forming compounds.

This investigation demonstrates that the analysis of UCMs can provide important information about the biological source and diagenetic history of the sedimentary organic matter. 
The II UCMs appear to result from the diagenetic alteration of biogenic material via a coupled process of isomerization and hydrocarbon cracking. The isomerization of these compounds was likely caused by thermal stress in the presence of high hydrogen pressure. Such conditions are common within hydrothermal environments. 


\section{Acknowledgements}

We thank Porcupine Joint Venture and The Ministry of Northern Mines and Development (Ontario, Canada) for access to the gold mines and for samples. We also thank Eric Barr and Alastair Still for their help with sampling. We would also like to extend warm, but sadly belated thanks to Richard Keele, who has since passed away. It was through his initial organization and supervision that samples were collected. We thank R.E. Summons and E. Grosjean for MRM-GCMS analysis. This project was supported by NASA Exobiology grant \#NAG5-13446 to Fabien Kenig. GC $\times$ GC analysis was supported by NSF grant IIS-0430835 and the Seaver Foundation to Christopher M. Reddy. Preparation of the archaeal biphytane standard was supported by NSF grant ARC-0520226 to Benjamin Van Mooy. 


\section{REFERENCES}

Akhmedow, V.M., Al-Khowaiter, S.H., Akhmedow, E., Sadikhow, A., 1999. Low temperature hydrocracking of hydrocarbons on Ni-supported catalysts. Appl. Cat. A: General 181, 51-61.

Aitken, C.M., Jones, D.M., Larter, S.R., 2004. Anaerobic hydrocarbon biodegradation in deep subsurface oil reservoirs. Science 431, 291-294.

Alexander, R., Cumbers, M., Kagi, R., Offer, M. and Taylor, R., 1982. Petroleum contamination of Cockburn Sound, Western Australia. Toxicology Environmental Chemistry 5, 251275.

Annweiler, E., Michaelis, W. and Meckenstock, R.U., 2002. Identical ring cleavage products during anaerobic degradation of naphthalene, 2-methylnaphthalene, and tetraline indicate a new metabolic pathway. Applied Environmental Microbiology 68, 852-858.

Armanios, C., Alexander, R., Kagi, R.I., Sosrowidjojo, I.B., 1994. Fractionation of sedimentary higher-plant derived pentacyclic triterpanes using molecular sieves. Organic Geochemistry 21, 531-543.

Ayer, J.A., Ketchum, J.W.F., Trowell, N.F., 2002. New geochronological and neodymium isotopic results from the Abitibi greenstone belt, with emphasis on the timing and the tectonic implications of Neoarchean sedimentation and volcanism; in Summary of Field Work and Other Activities 2002, Ontario Geological Survey, Open File Report 6100. 5-1 to $5-16$.

Biller, J.E., Biemann, K., 1974. Reconstructed mass spectra, a novel approach for the utilization of gas chromatograph-mass spectrometer data. Analytical Letters 7(7), 515-528.

Bost, F.D., Frontera-Suau, R., McDonald, T.J., Peters, K.E., Morris, P.J., 2001. Aerobic biodegradation of hopanes and norhopanes in Venezuelan crude oils. Organic Geochemistry 32, 105-114.

Brassell, S.C., Wardroper, A.M.K., Thomson, I.D., Maxwell, J.R., Eglinton, G., 1981. Specific acyclic isoprenoids as biological markers of methanogenic bacteria in marine sediments. Nature 290, 693-696.

Brisbin, D.I., 1997. Geological setting of gold deposits in the Porcupine gold camp, Timmins, Ontario. Queens's University, Kingston, ON, Canada. Ph.D. Thesis.

Brocks, J.J., Buick, R., Logan, G.A., and Summons, R.E., 2003. Composition and syngeneity of molecular fossils from the 2.78 to 2.45 billion-year-old Mount Bruce Supergroup, Pilbara Craton, Western Australia. Geochimica et Cosmochimica Acta 67, 4289-4319. 
Brocks, J.J., Grosjean, E., Logan, G.A., 2008. Assessing biomarker syngeneity using branched alkanes with quaternary carbon (BAQCs) and other plastic contaminants. Geochimica et Cosmochimica Acta 72, 871-888.

Chappe, B., Albrecht, P. and Michaelis, W., 1982. Polar lipids of archaebacteria in sediments and petroleums. Science 217, 65-66.

Chappe, B., Michaelis, W., and Albrecht, P., 1979. Molecular fossils of Archaebacteria as selective degradation products of kerogen. In: Advances in Organic Geochemistry 1979. Ed. Douglas, A.G., Maxwell, J.R. Pergamon Press 265-274.

Chappe, B., Michaelis, W., Albrecht, P., Ourisson, G., 1979. Fossil evidence for a novel series of archaebacterial lipids. Naturwissenschaften 66(10), 522-525.

Connan, J., 1984. Biodegradation of crude oils in reservoirs. In: Brooks, J., Welte, D.H. (Eds.). Advances in Petroleum Geochemistry 1. Academic Press, London 300-330.

Dagan, S., 2000. Comparison of gas chromatography-pulsed flame photometric detection-mass spectrometry, automated mass spectral deconvolution and identification system and gas chromatography - tandem mass spectrometry as tools for trace level detection and identification. Journal of Chromatography A. 868, 229-247.

Davies, J.F. ,Whitehead, R.E., 1994. Molar ratios in the study of unaltered and hydrothermally altered greywackes and shales. Chemical Geology 111, 85-100.

DeLong, E.F., King, L.L., Massana, R., Cittone, H., Murray, A., Schleper, C., Wakeham, S.G., 1998. Dibiphytanyl ether lipids in nonthermophilic crenarchaeotes. Applied and Environmental Microbiology 64 (3), 1133-1138.

Demir, C., Hindmarch, P., Brereton, R.G., 2000. Deconvolution of a three-component coeluting peak cluster in gas chromatography - mass spectrometry. Analyst 125, 287-292.

De Rosa, M., Gambacorta, A., 1988. The lipids of Archaebacteria. Progress in Lipid Research 27, 153-175.

De Rosa, M., Gambacorta, A., Nicolaus, B., Sodano, S., and Bu'Lock, J.D., 1980. Structural regulations in tetraether lipids of Caldariella and their biosynthetic and phyletic implications Phytochemistry 19, 833-836.

Dimroth, E., Imreh, L., Rocheleau, M., and Goulet, N. 1982., Evolution of the south-central part of Archean Abitibi belt. Part I. Stratigraphy and paleogeographical model: Canadian Journal of Earth Science 19, 1729-1758.

Eglinton, G., Maxwell, J.R. and Philp, R.P., 1975. Organic geochemistry of sediments from contemporary aquatic environments. In Advances in Organic Geochemistry. 1973. (Ed. Tissot, B. and Bienner, F.) 941-961. 
Ellis, L. Alexander, R., Kagi, R.I., 1994. Separation of petroleum-hydrocarbons using dealuminated mordenite molecular-sieve. 2. Alkylnaphthalenes and alkylphenanthrenes. Organic Geochemistry 21, 849-855.

Ernst, M., Freisleben, H.-J., Antonopoulos, E., Henkel, L., Mlekusch, W., and Reibnegger, G., 1998. Calorimetry of archaeal tetraether lipid - indication of a novel metastable thermotropic phase in the main phospholipid from Thermoplasma acidophilum cultured at $59^{\circ} \mathrm{C}$. Chemistry and Physics of Lipids. 94, 1-12.

Fazeelat, T., Alexander, R., Kagi, R.I., 1994. Extended 8,14-secohopanes in some seep oils from Pakistan. Organic Geochemistry 21, 257-264.

Fierro, V., Schuurman, Y., Mirodatos, C., Duplan, J.L., Verstaete, J., 2002. Study of the cracking reaction of linear and branched hexanes under protolytic conditions by nonstationary kinetics. Chemical Eng. J. 90, 139-147.

Fowler, M.G., Abolins, T,P. and Douglas, A.G. 1986. Monocyclic alkanes in Ordovician organic matter. Organic Geochemistry 10, 815-823.

Frysinger, G.S. and Gaines, R.B., 2001. Separation and identification of petroleum biomarkers by comprehensive two-dimensional gas chromatography. Journal of Separation Science 24, 87-96.

Frysinger, G.S., Gaines, R.B., Xu, L., Reddy, C.M., 2003. Resolving the unresolved complex mixture in petroleum-contained sediments. Environmental Science and Technology 37, 1653-1662.

Fyon, J.A., Crocket, J.H., and Schwarcz, H.P., 1983. Magnesite abundance as a guide to gold mineralization associated with ultramafic flows, Timmins Area. Journal of Geochemical Exploration 18, 245-266.

Gattinger, A., Schloter, M., Munch, J.C. 2002. Phospholipid etherlipid and phospholipid fatty acid fingerprints in selected euryarchaeotal monocultures for taxonomic profiling. FEMS Microbiological Letters 213 (1): 133-139.

Goldstein, T.P., 1983. Geocatalytic reactions in formation and maturation of petroleum. American Association of Petroleum Geologists Bulletin 67, 152-159.

Golovkina, L.S., Rusinova, G.V., and Petrov, A.I.A. 1984. Mass Spectrometry of Saturated Hydrocarbons. Russian Chemical Reviews 53, 1493-1522.

Gough, M.A., Rowland, S.J., 1990. Characterization of unresolved complex-mixtures of hydrocarbons in petroleum. Nature 334, 648-650.

Gough, M.A., Rhead, M.M., Rowland, S.J., 1992. Biodegradation studies of unresolved complex mixtures of hydrocarbons: model UCM hydrocarbons and the aliphatic UCM. Organic Geochemistry 18, 17-22. 
Grosjean, E., Logan, G.A., 2007. Incorporation of organic contaminants into geochemical samples and an assessment of potential sources: Examples from Geoscience Australia marine survey S282. Organic Geochemistry 38, 853-869.

Hoffmann, C.F, Foster, C.B., Powell, T.G., Summons, R.E., 1987. Hydrocarbon biomarkers from Ordovician sediments and the fossil alga Gloeocapsomorpha prisca Zalessky 1917. Geochimica et Cosmochimica Acta 51, 2681-2697.

Hopmans, E.C., Schouten, S., Pancost, R.D., van der Meer, M.T.J., Damste, J.S.S. 2000. Analysis of intact tetraether lipids in archaeal cell material and sediments by high performance liquid chromatography/atmospheric pressure chemical ionization mass spectrometry. Rapid Communications in Mass Spectrometry 14 (7), 585-589.

Johnson, C.G., Frysinger, G.S., Nelson, R.K., Gaines, N., Ohkouchi, Reddy, C.M., Eglinton, T.J., 2003. Innovative methods for determining alkenone unsaturation indices. Marine Chemistry 83, 5-22.

Kates, M., 1997. Diether and tetraether phospholipids and glycolipids as molecular markers for Archaebacteria (Archaea). In Molecular Markers in Environmental Geochemistry (ed. R.P. Eganhouse). American Chemical Society 35-48.

Kerrich, R., Fryer, B.J., King, R.W., Willmore, L.M. and Van Hees, E., 1987. Crustal outgassing and LILE enrichment in major lithosphere structures, Archean Abitibi greenstone belt: Evidence on the source reservoir from strontium and carbon isotope tracers. Contributions to Mineralogy and Petrology. 97, 156-168.

Kerrich, R. Ludden, J., 2000. The role of fluids during formation and evolution of the southern Superior Province lithosphere: an overview. Canadian Journal of Earth Science 37, 135164.

Killops, S.D., All-Juboori, M.A.H.A., 1990. Characterization of the unresolved complex mixture (UCM) in the gas chromatograms of biodegraded petroleums. Organic Geochemistry 15, 147-160.

Killops, S.D., Killops, V.J. 2005. Introduction to Organic Geochemistry, 2nd Ed. 152. Blackwell Publishing.

Kiselev A.V., Kulikov N.S., Curthoys G., 1984. Gas chromatography - mass spectrometry of the steroisomers of perhydroanthracene and perhydrophenanthrene. Chromatographia 18, 6, 297-304.

Kvenvolden, K.A., Simoneit, B.R.T., 1990. Hydrothermally derived petroleum: examples from Guaymas Basin, Gulf of California and Escanaba Trough, Northeast Pacific Ocean. American Association of Petroleum Geologists Bulletin 74, 223-237.

Lewan, M.D., 1997. Experiments on the role of water in petroleum formation.Geochimica et 
Cosmochimica Acta 61, 3691-3723.

Liu, J., Phillips, J.B., 1991. Comprehensive two-dimensional gas chromatography using an oncolumn thermal modulator interface. Journal of Chromatographic Science 29, 227-231.

Liu, X., Bi, X., Sheng, G., Fu, J., 2005. Separation of PAHs in aerosol by thin layer chromatography for compound-specific stable carbon isotope analysis. Talanta 66, 487494.

McLafferty, F. W. and Stauffer, D. B., 1989. The Wiley/NBS registry of mass spectral data. Vol. 2, John Wiley and Sons, New York, Pg. 2121.

McLafferty and Tureček, F., 1993. Interpretation of Mass Spectra. $4^{\text {th }}$ Ed. University of Science Books 232-233.

Meckenstock, R.U., Safinowski, M., Griebler, C. 2004. Anaerobic degradation of polycyclic aromatic hydrocarbons. MiniReview. FEMS Microbiology Ecology 49, 27-36.

Montenegro, E., Gabler, B., Paradies, G., Seemann, M., Helmchen, G. 2003. Determination of the configuration of an archaea membrane lipid containing cyclopentane rings by total synthesis. Angewandte Chemie, International Edition 42(21), 2419-2421.

Morii, H., Eguchi, T., Nishihara, M., Kakinuma, K., Konig, H., Koga, Y. 1998. A novel ether core lipid with $\mathrm{H}$-shaped $\mathrm{C} 80$-isoprenoid hydrocarbon chain from the hyperthermophilic methanogen Methanothermus fervidus. Biochimica et Biophysica Acta, Lipids and Lipid Metabolism 1390(3), 339-345.

Morrison R.T., Boyd, R.N., 1973. Organic Chemistry. $3^{\text {rd }}$ Ed. New York University. Allyn and Bacon, Inc. Boston.

Nelkenbaum, E., Dror, I. and Berkowitz, B., 2007. Reductive hydrogenation of polycyclic aromatic hydrocarbons catalyzed by metalloporphyrins. Chemosphere, 68, 2, 210-217.

Ogihara, S., Ishiwatari, R., 1998. Unusual distribution of hydrocarbons in a hydrothermally altered phosphorite nodule from Kusu Basin, northern Kyushu, Japan. Organic Geochemistry 29, 155-161.

Palmer, S.E., 1993. Effect of biodegradation and water washing on crude oil composition. In: Engel, M.H., Macko, S.A. (Eds.), Organic Geochemistry. Plenum Press, New York 511533.

Payzant J.D., Rubinstein I., Hogg A.M., O.P. Strausz., 1979. Field-ionization mass spectrometry: Application to geochemical analysis. Geochimica et Cosmochimica Acta 43, 1187-1193.

Payzant, J.D., Rubinstein, I., Hogg, A.M., Strausz, O.P., 1980. Analysis of Cold Lake Bitumen Hydrocarbons Combined GLC - Field Ionization Mass Spectrometry and GLC Electron Impact Mass Spectrometry. Chemical Geology 29, 73-88. 
Pease, T. K., Van Vleet, E.S., Barre, J.S. 1992. Diphytanyl glycerol ether distributions in sediments of the Orca Basin. Geochimica et Cosmochimica Acta 56, 3469-3479.

Peters, K.E., Moldowan, J.M., 1993.The Biomarker Guide. Interpreting Molecular Fossils in Petroleum and Ancient Sediments. Prentice Hall, New York.

Petrov, A.A., Vorobyova, N.S., and Zemskova, Z.K., 1990. Isoprenoid alkanes with irregular "head-to-head" linkages. Advanced Organic Geochemistry. 16, 1001-1005.

Phillips, G.M., 1986. Geology and alteration in the Golden Mile, Kalgoorlie. Economic Geology. 81, 779-808.

Pool, W.G., de Leeuw, J.W., van de Graaf, B., 1997. Automated extraction of pure mass spectra from gas chromatographic mass spectrometric data. Journal of Mass Spectometry 32, 438-443.

Price, L.C., DeWitt, E., 2001. Evidence and characteristics of hydrolytic disproportionation of organic matter during metasomatic processes. Geochimica et Cosmochimica Acta 65, 3791-3826.

Reddy, C.M., Eglinton, T.I., Hounshell, A., White, H.K., Xu, L., Gaines, R.B., Frysinger, G.S., 2002. The West Falmouth Oil Spill after thirty years: The persistence of petroleum hydrocarbons in marsh sediments. Environmental Science and Technology 36, 47544760 .

Reddy, C.M., Nelson, R.K., Sylva, S.P., Xu, L., Peacock, E.A., Raghuraman, B., Mullins, O.C., 2007. Identification and quantification of alkene-based drilling fluids in crude oils by comprehensive two-dimensional gas chromatography with flame ionization detection. Journal of Chromatography A 1148 (1), 100-107.

Revill, A.T., 1992. Characterization of unresolved complex mixtures of hydrocarbons by degredative methods. Ph.D. Thesis, University of Plymouth, UK.

Rice, R.J., Born, P., Donaldson, J.A. 1992., Archean sedimentology and stratigraphy: Dore metasediments, Michipicoten, greenstone belt, Timiskaming and Porcupine metasediments, Abitibi greenstone belt. In: Geoscience Research Grant Program, Summary of Research 1991-1992. Ontario Geological Survey Miscellaneous Paper. 159. 3-16.

Roberts, R.G., 1987. Ore deposit models - 11: Archean lode gold deposits. Geoscience Canada 14, 37-52.

Rowland, S.J., Alexander, R., Kagi, R.I., Jones, D.M., Douglas, A.G., 1986. Microbial degradation of aromatic components of crude oils: a comparison of laboratory and field observations. Organic Geochemistry 9, 153-161. 
Rowland, S.J., Maxwell, J.R., 1984. Reworked triterpenoid and steroid hydrocarbons in a recent sediment. Geochimica et Cosmochimica Acta 48, 617-624.

Rubinstein, I., Siekind, O., and Albrecht, P., 1975. Rearranged sterenes in a shale: occurrence and simulated formation. Journal of Chemical Society, Perkin Transactions I 1833-1836.

Rubinstein, I., Strausz, O. P., 1979. Thermal treatment of the Athabasca oil sand bitumen and its component parts. Geochimica et Cosmochimica Acta 43(12), 1887-93.

Rullkötter, J., Aizenshtat, Z. and Spiro, B., 1984. Biological markers in bitumens and pyrolysates of Upper Cretaceous bituminous chalks from the Ghareb Formation (Israel). Geochimica et Cosmochimica Acta 48, 141-157.

Rushdi, A.I., Simoneit, B.R.T., 2002a. Hydrothermal alteration of organic matter in sediments of the Northeastern Pacific Ocean: Part 1. Middle Valley, Juan de Fuca Ridge. Applied Geochemistry 17, 1401-1428.

Rushdi, A.I., Simoneit, B.R.T., 2002b. Hydrothermal alteration of organic matter in sediments of the Northeastern Pacific Ocean: Part 2. Escanaba Trough, Gorda Ridge. Applied Geochemistry 17, 1467-1494.

Sanders, P.F., Tibbetts, P.J.C., 1987. Effects of discarded drill muds on microbial populations. Philosophical Transactions of the Royal Academy of Sciences London. 316, 567-585.

Schouten, S., Hoefs, M.J., Koopmans, M.R., Bosch, H.-J., and Sinninghe Damste, J.S., 1998. Structural characterization, occurrence and fate of archaeal ether bound acyclic and cyclic biphytanes and corresponding diols in sediments. Organic Geochemistry 29, 1305-1319.

Schouten, Stefan, Hopmans, Ellen C., Pancost, Richard D., Sinninghe Damste, J.S., 2000. Widespread occurrence of structurally diverse tetraether membrane lipids: Evidence for the ubiquitous presence of low-temperature relatives of hyperthermophiles. Proceedings of the National Academy of Sciences of the United States of America. 97, 14421-14426.

Seewald, J.S., 1994. Evidence for metastable equilibrium between hydrocarbons under hydrothermal conditions. Nature 370, 285-287.

Seewald, J.S., 2003. Organic - inorganic interactions in petroleum-producing sedimentary basins. Nature 426, 327-333.

Simons, D.J.H., Kenig, F., 2001. Molecular fossil constraints on the water column structure of the Cenomanian-Turonian Western Interior Seaway, USA. Paleogeography, Paleoclimatology, Paleoecology 169, 129-152.

Simoneit, B.R.T., 1994. Lipid/bitumen maturation by hydrothermal activity in sediments Middle Valley, Leg 139. In Mottle, M., Davis, E.E., Fisher, A.T., Slack, J.F. (Eds), Proc. Ocean Drilling Program, Scientific Results. Vol. 139. College Station. 447-465. 
Simoneit, B.R.T., Goodfellow, W.D., Franklin, J.M., 1992. Hydrothermal petroleum at the seafloor and organic matter alteration in sediments of Middle Valley, Northern Juan de Fuca Ridge. Applied Geochemistry 7, 257-264.

Simoneit, B.R.T., Lein, A.Y., Peresypkin, V.I., Osipov, G.A., 2004. Composition and origin of hydrothermal petroleum and associated lipids in the sulfide deposits of the Rainbow Field (Mid-Atlantic Ridge at $36^{\circ} \mathrm{N}$ ). Geochimica et Cosmochimica Acta 68, 2275-2294.

Simoneit, B.R.T., Lonsdale, P.F., 1982. Hydrothermal petroleum in mineralized mounds at the seabed of Guaymas Basin. Nature 295, 198-202.

Simoneit, B.R.T., Philp, R.D., Galimov, E.M., 1984. Organic geochemistry of Deep Sea Drilling Project sediments from the Gulf of California - hydrothermal effects on unconsolidated diatom ooze. Organic Geochemistry 7, 173-205.

Sinninghe Damsté, J.S., Hopmans, E.C., Schouten, S., van Duin A.C.T., Geenevasen, J.A.J., 2002. Crenarchaeol: the characteristic core glycerol dibiphytanyl glycerol tetraether membrane lipid of cosmopolitan pelagic crenarchaeota. Journal of Lipid Research 43, 1641-1651.

Sprott, G.D., Agnew, B.J., Patel, G.B., 1997. Structural features of ether lipids in the archaeobacterial thermophiles Pyrococcus furiosus, Methanopyrus kandleri, Methanothermus fervidus, and Sulfolobus acidocaldarius Canadian Journal of Microbiology 43 (5), 467-476.

Stefanova, M., 2000. Head-to-head linked isoprenoids in Miocene coal lithotypes. Fuel 79, 755 758.

Sutton, P.A., Lewis, C.A., Rowland, S.J., 2005. Isolated of individual hydrocarbons from the unresolved complex hydrocarbon mixture of a biodegraded crude oil using preparative capillary gas chromatography. Organic Geochemistry 36, 963-970.

Swannell, R.P.J., Croft, B.C., Grant, A.L., Lee, K., 1995. Evaluation of bioremediation agents in beach microcosms. Spill Science and Technology Bulletin 2, 151-159.

Tannenbaum, E. Kaplan, I.R., 1985. Role of minerals in thermal alteration of organic matter - II: A material balance. American Association of Petroleum Geologists Bulletin 70, 708-709.

Tannenbaum, E., Ruth, E., Kaplan, I.R., 1986. Steranes and triterpanes generated from kerogen pyrolysis in the absence and presence of minerals. Geochimica et Cosmochimica Acta 50, 805-812.

Thompson, P.H., 2002. Toward a new metamorphic framework for gold exploration in the 
Timmins Area, Central Abitibi Greenstone Belt. Ontario Geological Survey. Open File Report 6101. Poster.

Ventura, G.T., 2006. Biomarkers of hydrothermally altered, Late Archean metasediments from the Abitibi Subprovince, Canada. Ph.D. Thesis, University of Illinois at Chicago, Il. USA.

Ventura, G. T., Kenig, F., Reddy, C. M., Schieber, J., Frysinger, G.S., Nelson, R.K., Dinel, E., Gaines, R.B., Schaeffer, P., 2007. Molecular evidence of Late Archean archaea and the presence of a subsurface hydrothermal biosphere. Proceedings of the National Academy of Sciences 104 (36), 14261-14266.

Uda, I., Sugai, A., Itoh Y. H., and Itoh, T., 2001. Variation in molecular species of polar lipids from Thermoplasma acidophilum depends on growth temperature. Lipids, 36, 103-105.

Vink, A., Schouten, S., Sephton, S., Sinninghe Damsté, J.S., 1998. A newly discovered norisoprenoid, 2,6,15,19-tetramethylicosane, in Cretaceous black shales. Geochimica et Cosmochimica Acta 62, 965-970.

Veizer, J., Hoefs, J., Lowe, D.R., Thurston, P.C., 1989. Geochemistry of Precambrian carbonates: II. Archean greenstone belts and Archean sea water. Geochimica et Cosmochimica Acta 53 (4): 859-871.

Volkman, J.K. Maxwell, J.R., 1986. Acyclic isoprenoids as biological markers. In Biological Markers in the Sedimentary Record. (ed. R. B. Johns). 1-42. Elsevier.

Warton, B., 1999. Studies of the saturate and aromatic hydrocarbon unresolved complex mixtures in petroleum. Ph.D. Thesis, Curtin University of Technology, Perth, Australia.

Warton, B., Alexander, R., Kagi, R.I., 2000. Characterization of the ruthenium tetroxide oxidation products from the aromatic unresolved complex mixture of a biodegraded crude oil. Organic Geochemistry 30, 1255-1272.

Yamanaka, T., Ishibashi, J., Hashimoto, J., 2000., Organic geochemistry of hydrothermal petroleum generated in the submarine Wakamiko caldera, southern Kyushu, Japan. Organic Geochemistry 31, 1117-1132.

Yuan, T., Marshall, W.D., 2005., Catalytic hydrogenation of polycyclic aromatic hydrocarbons over palladium/c-Al2O3 under mild conditions. Journal of Hazard Materials. 126, 149157.

Zarate-del Valle, P.F., Simoneit, B.R.T., 2005. Hydrothermal bitumen generated from sedimentary organic matter of rift lakes - Lake Chapala, Citala Rift, western Mexico. Applied Geochemistry 20, 2343-2350. 


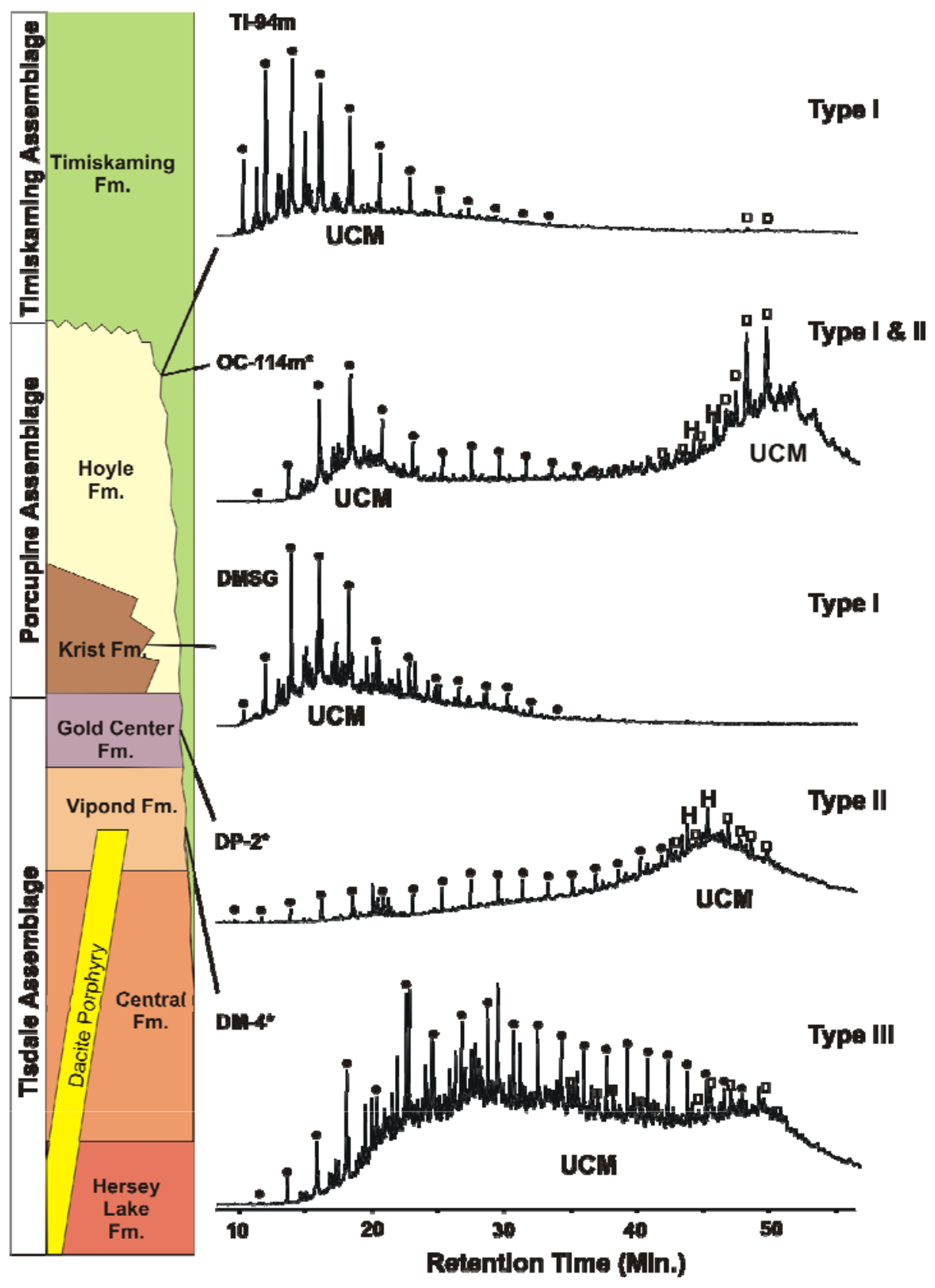

Figure 1. Stratigraphic profile of the PGC (left). Total ion current (TIC) chromatograms of the extractable hydrocarbon fraction of representative samples Tisdale and Porcupine Group (right). Unresolved complex mixtures (UCMs) are observed in samples from all the formations and are labeled "Type "I-III" in reference to their topology (see text). Filled circles indicate $n$-alkanes. Number above peak indicates numbers of carbon atoms in the compound. H indicates hopanes. Open squares indicate acyclic irregular isoprenoids, biphytane and derivatives. 

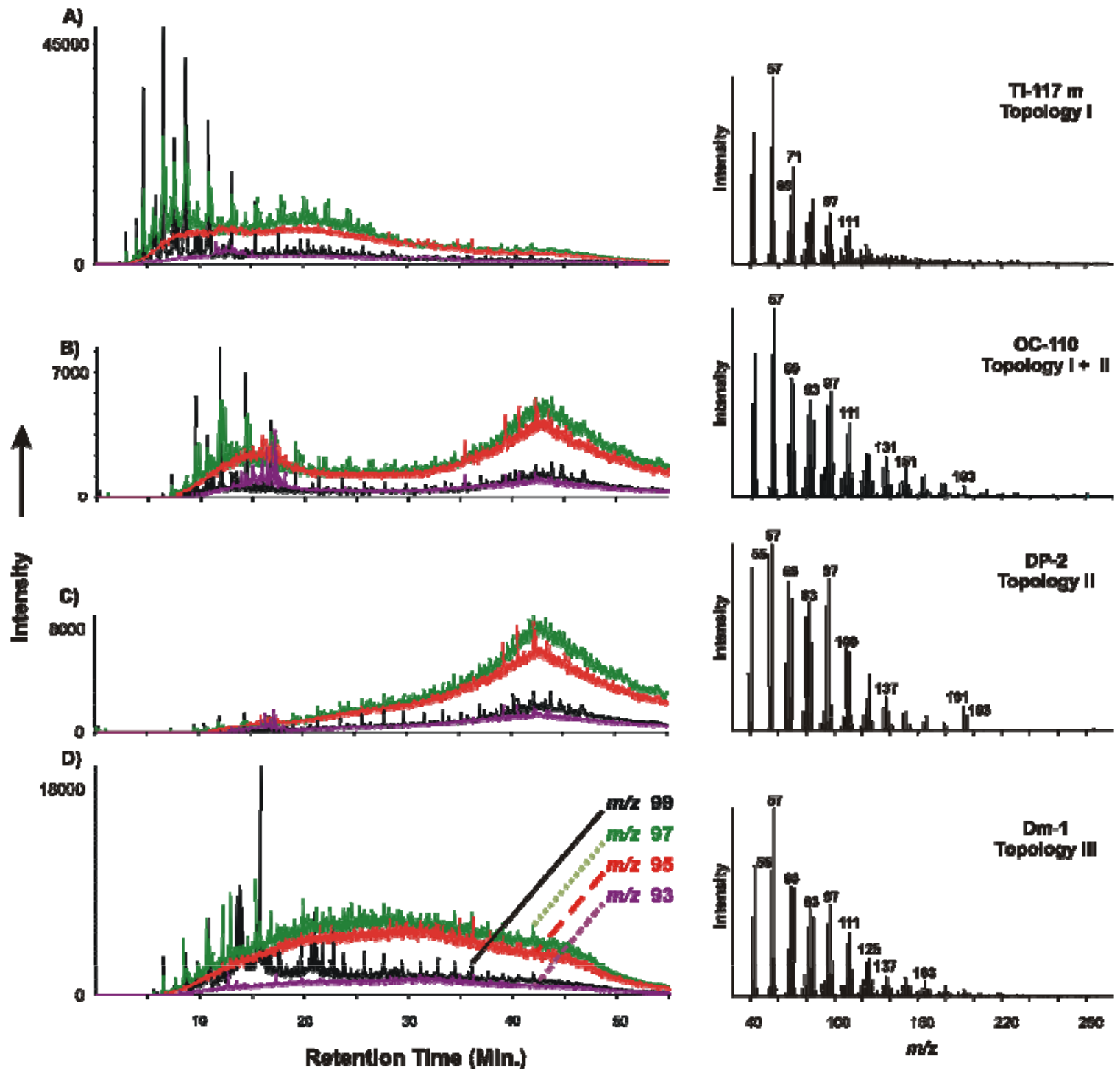

Figure 2. Mass chromatograms of fragment ions $\mathrm{m} / \mathrm{z} 99, \mathrm{~m} / \mathrm{z} 97, \mathrm{~m} / \mathrm{z} 95$ and $\mathrm{m} / \mathrm{z} 93$ (left) and mass spectra (right) of samples (A) TI-117 and (B) OC-110m of the Hoyle Formation; (C) DP-2 of the Gold Center Formation, and (D) DM-1 of the Vipond Formation. 

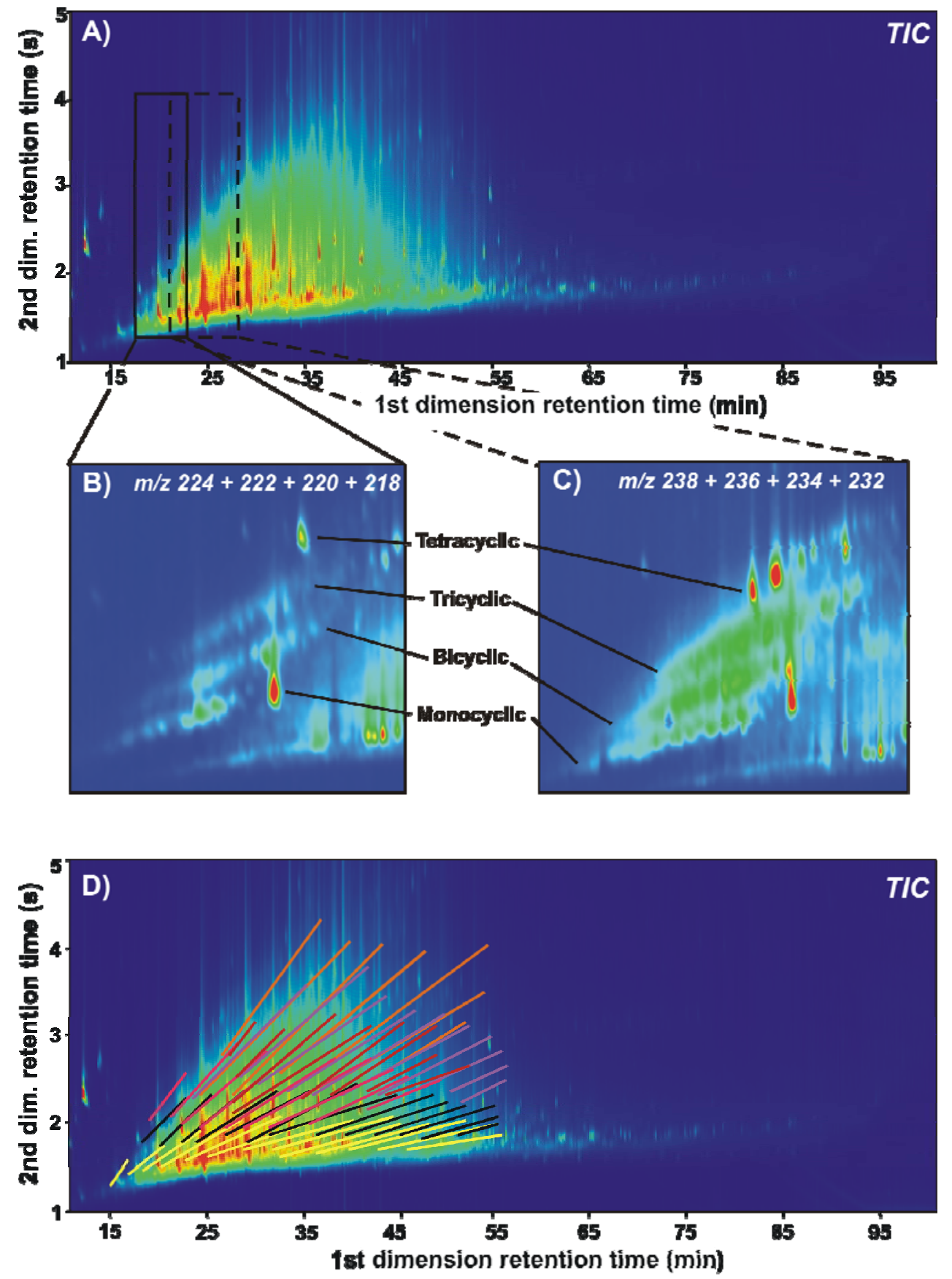

Figure 3. A) GC $\times$ GC-MS TIC chromatogram from the $\mathrm{s} / \mathrm{u} \mathrm{HC}$ fraction of the Krist Formation sample DMSD (Type I UCM). B) Partial, summed mass chromatogram of the fragment ions $\mathrm{m} / \mathrm{z}$ $224+222+220+198$ showing $\mathrm{C}_{16}$ mono-, bi-, tri-, and tetracyclic compounds. C) Partial, summed mass chromatogram of the fragment ions $\mathrm{m} / \mathrm{z} 238+236+234+232$ showing $\mathrm{C}_{17}$ mono-, bi-, tri-, and tetracyclic compounds. D) GC $\times$ GC-MS TIC chromatogram from the s/u $\mathrm{HC}$ fraction of the Krist Formation sample DMSD (Type I UCM) showing the lineaments of mono-, di-, tri-, tetra-, penta- and hexacyclic naphtenes. 


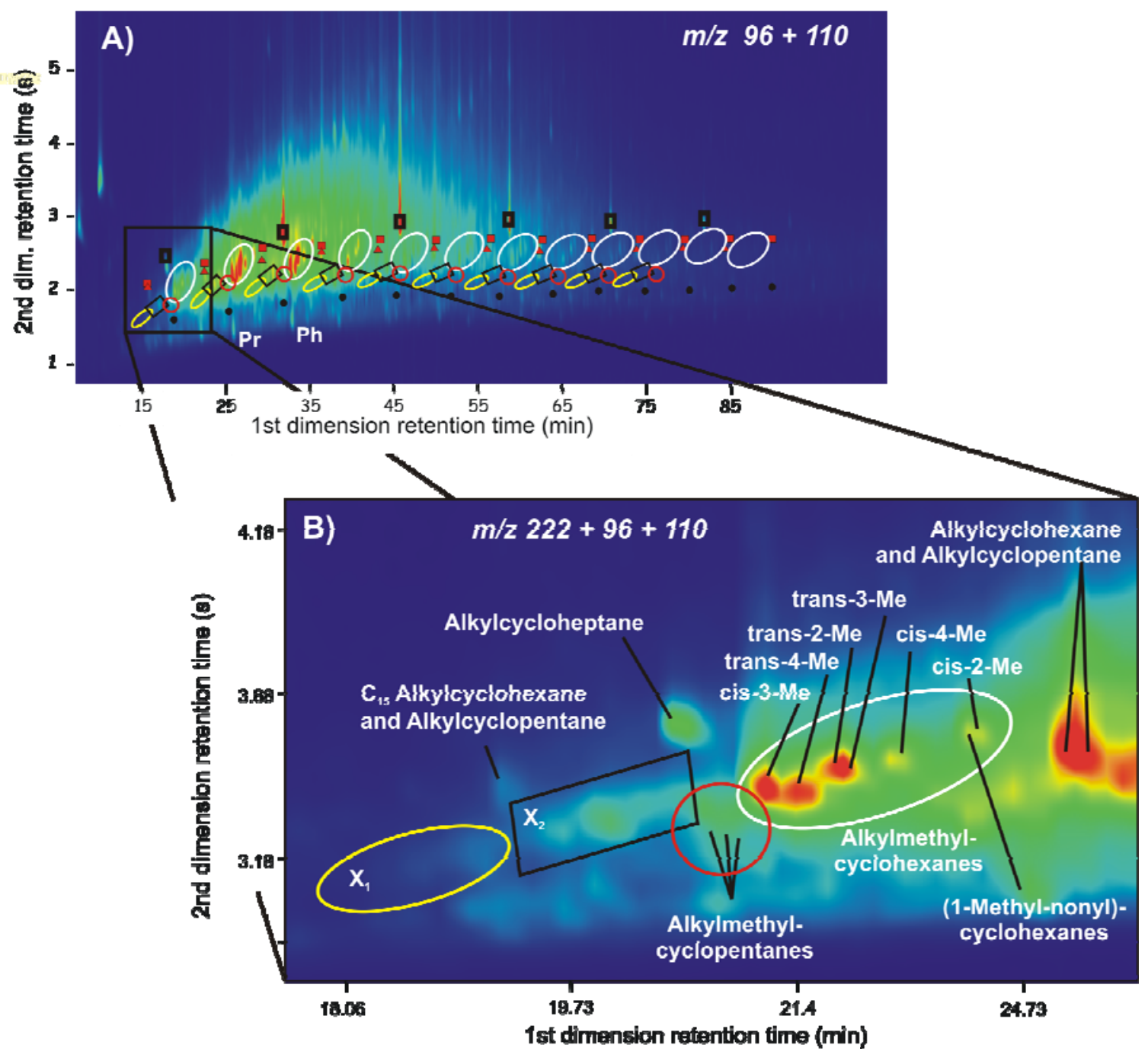

Figure 4. A) and B) GC $\times$ GC-MS mass chromatogram of the fragment ion $\mathrm{m} / \mathrm{z} 224+96+110$ of the $\mathrm{s} / \mathrm{u}$ HC fraction of the Krist Formation sample DMSD. $n$-alkanes are labeled with black dots, alkylcyclopentanes and alkylcyclohexanes are marked by red triangles and squares, respectively. Tentatively identified homologous series of alkylethylcyclohexanes, alkyldimethylcyclopentanes, alkylmethylcyclopentanes, alkylmethylcyclohexanes, and $n$ alkycycloheptanes are marked by yellow ellipses, black rectangles, red circles, larger white ellipses, small black boxes, respectively. 

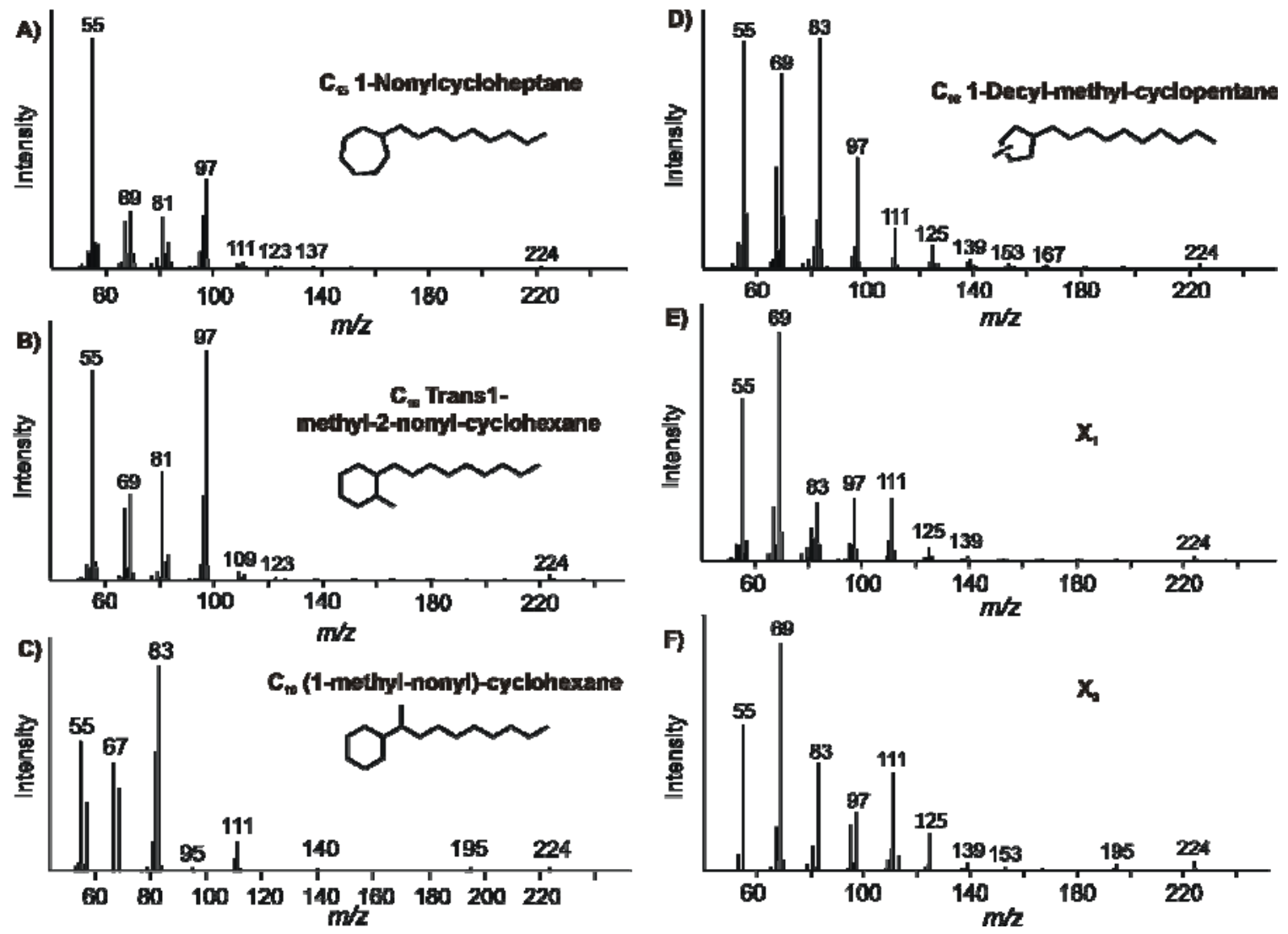

Figure 5. Mass spectra of tentatively identified $\mathrm{C}_{16} \mathrm{~A}$ ) alkylcycloheptane, $\mathrm{B}$ ) 1methylalkylcyclohexane, C) the trans-2-alkylmethylcyclohexane D) alkyldimethylcyclopentane, and $\mathrm{E}$ and $\mathrm{F}$ ) unidentified monocyclic labeled $\mathrm{X}_{1}$ and $\mathrm{X}_{2}$, respectively. 

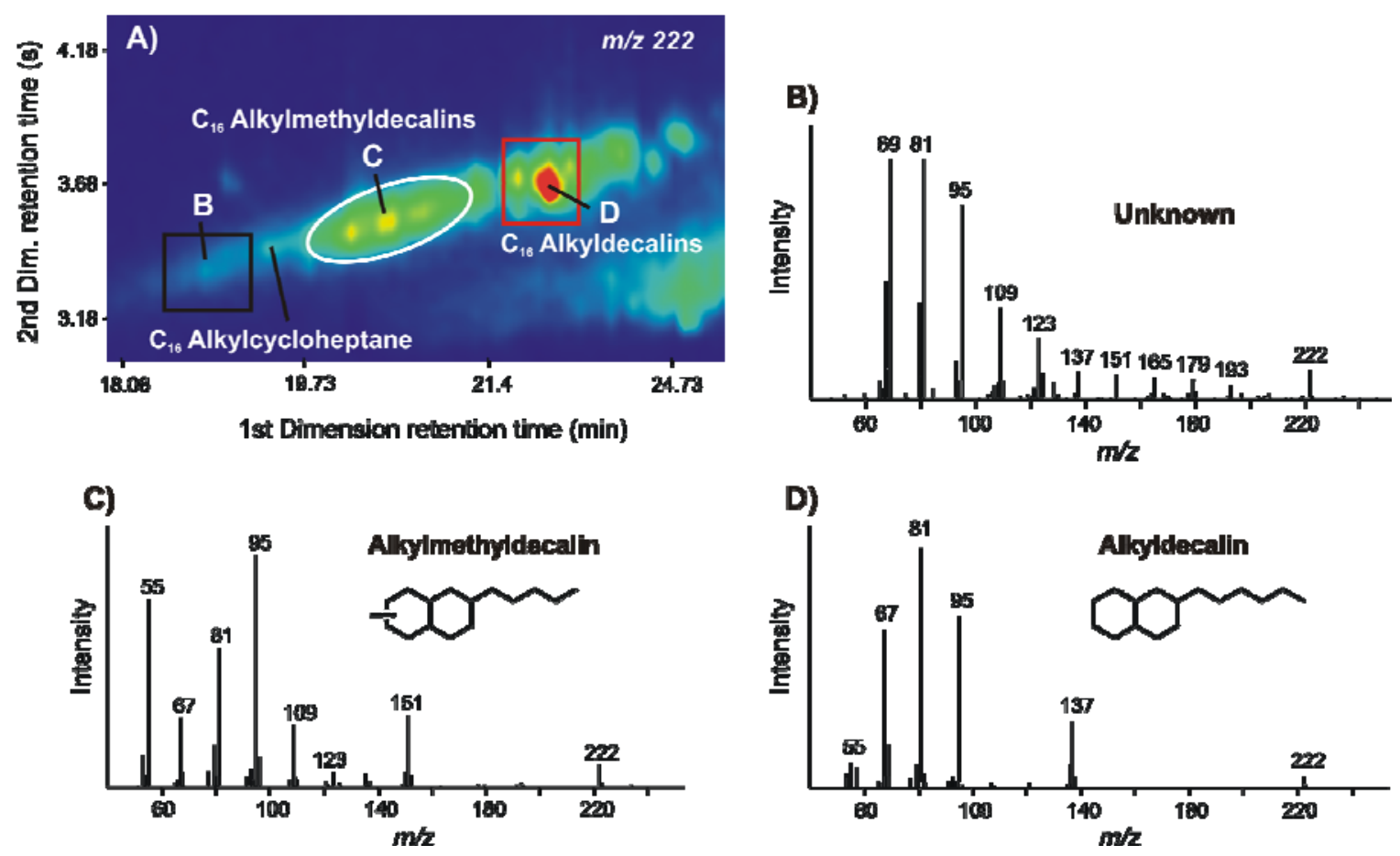

Figure 6. A) GC $\times$ GC-MS partial mass chromatogram of the fragment ion $m / z 222$ of the $s / u$ HC fraction of the Krist Formation sample DMSD, B), C), and D) are mass spectra of peaks B, C, and $\mathrm{D}$, respectively, in the mass chromatogram. C) and D) are representative mass spectra of peaks tentatively identified as alkylmethyldecalin and alkyldecalins. 

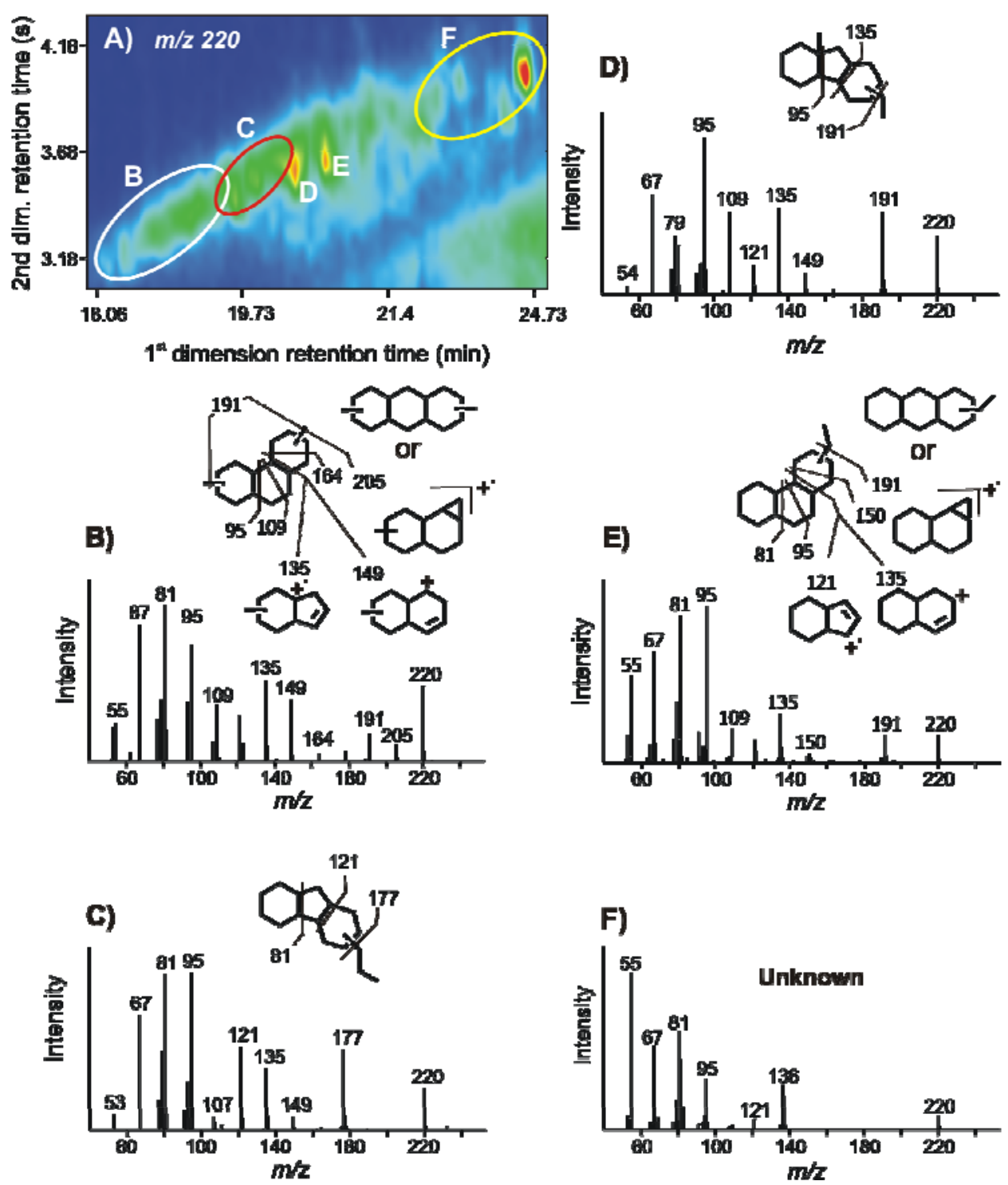

Figure 7. A) GC $\times$ GC-MS partial mass chromatogram of the fragment ion $m / z 220$ of the s/u HC fraction of the Krist Formation sample DMSD showing the distribution of $\mathrm{C}_{14}$ tricyclic compounds. Letters B), C), D), and F) are mass spectra for peaks inscribed by white (B), red (C) and yellow (F) ellipses and peaks D and E, respectively of the $\mathrm{m} / \mathrm{z} 220$ mass chromatogram. Possible fragmentation patterns are provided for B) and E) mass spectra. 


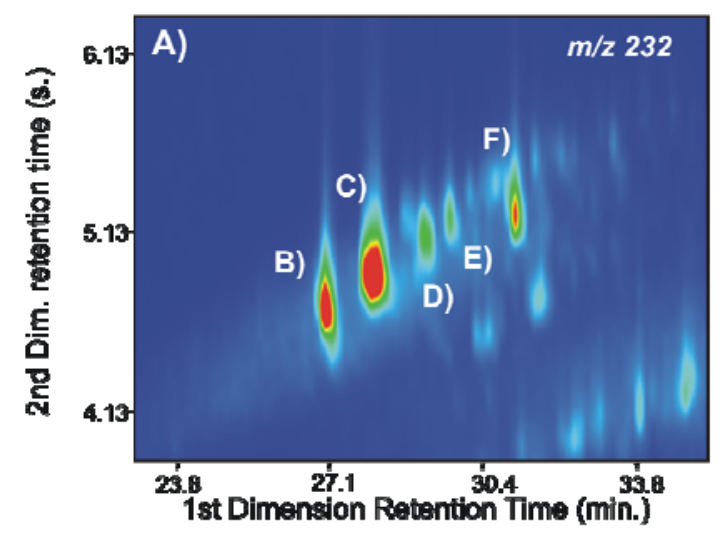

B) 1- or 2-methyl-hexadecahydro-pyrene

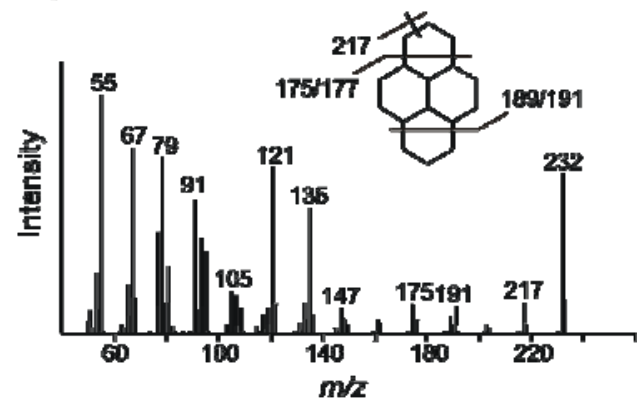

C) 1- or 2-methyl-hexadecahydro-pyrene
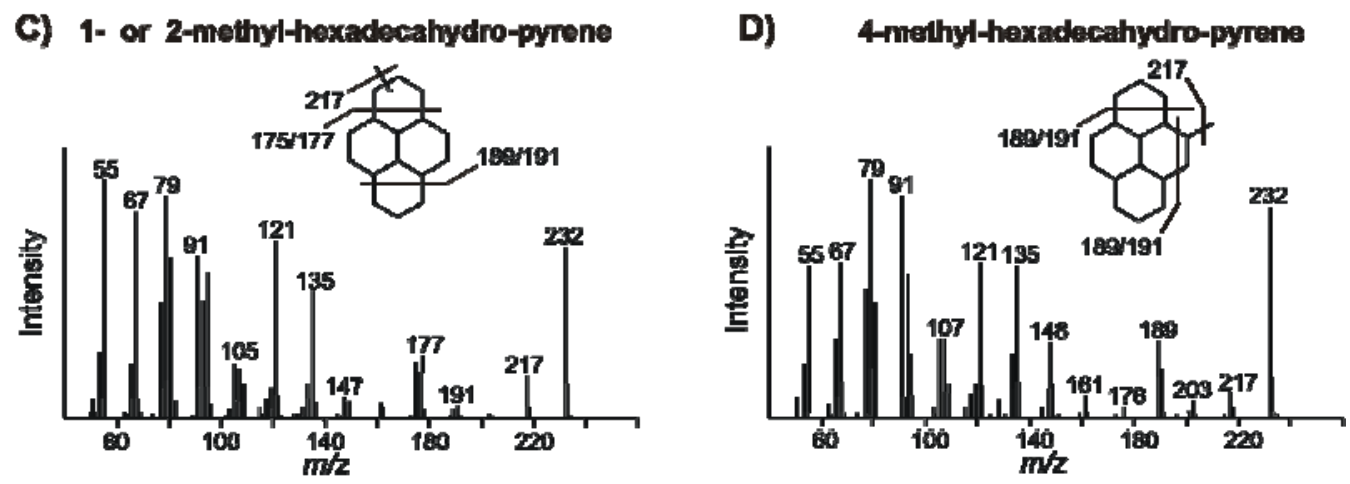

E)

F) hexadecahydro-berzo[de] anthracene
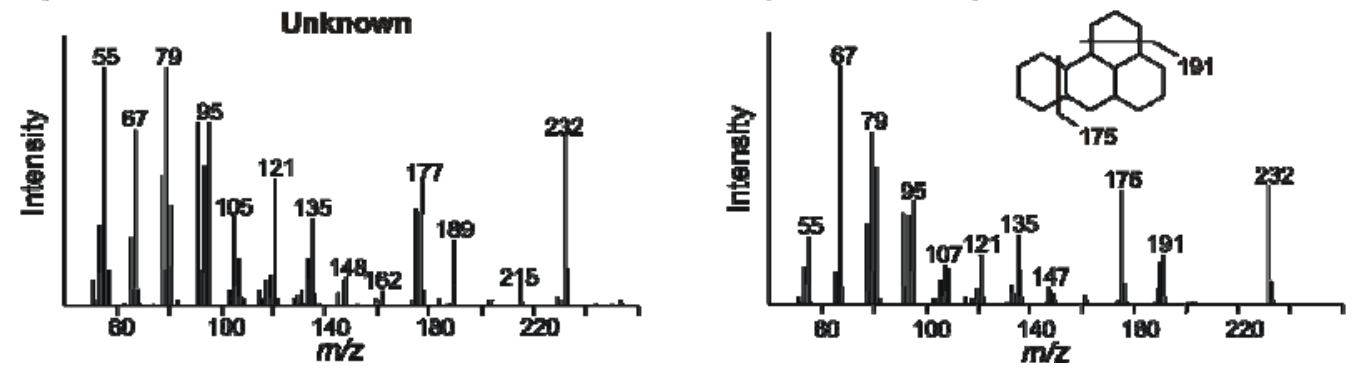

Figure 8. GC $\times$ GC-MS partial mass chromatogram of the fragment ion $m / z 232$ of the s/u HC fraction of the Krist Formation sample DMSD showing the distribution of $\mathrm{C}_{17}$ tetracyclic compounds. Letters marking the order of mass spectra correspond to the peaks labels of the mass chromatogram. 

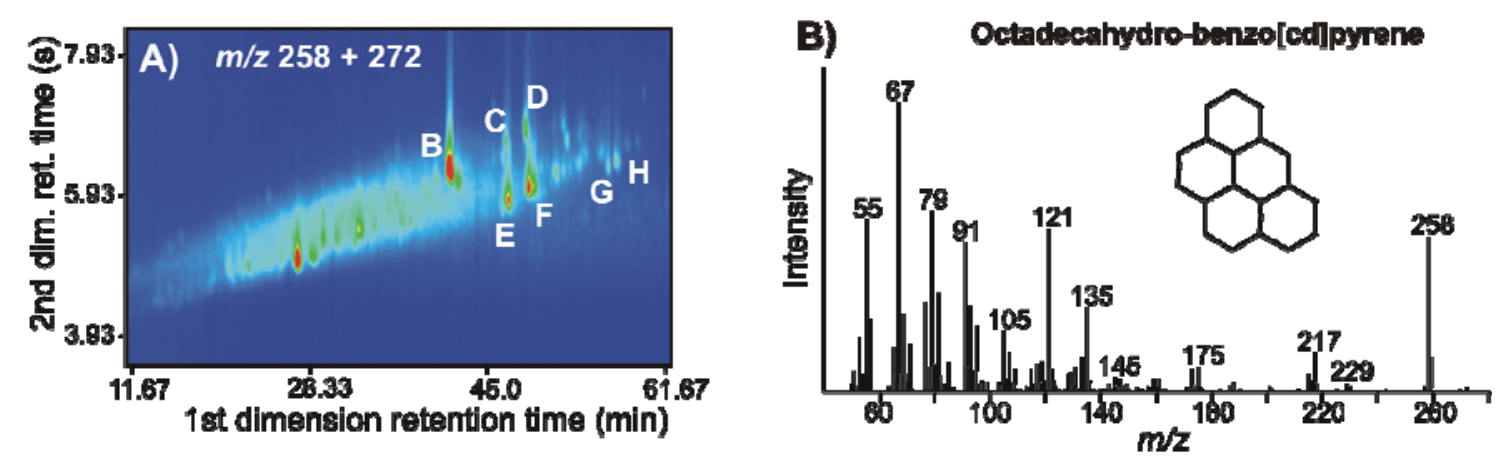

C) Methyl-octadecahydro-cyclopenta[cod]pynene

D) Octadecahydro-cyclopenta[e]pyrene
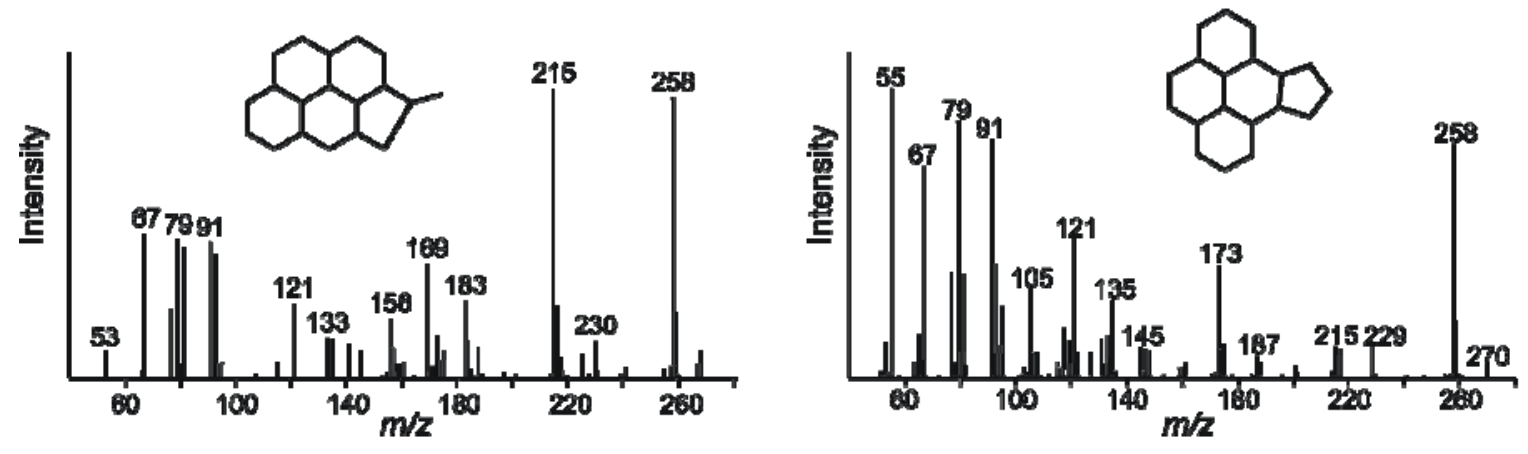

E) Octadecahydro- methylbenzo[cd]pyrene

F) Octadecahydro- methylbenzo[cd]pyrene
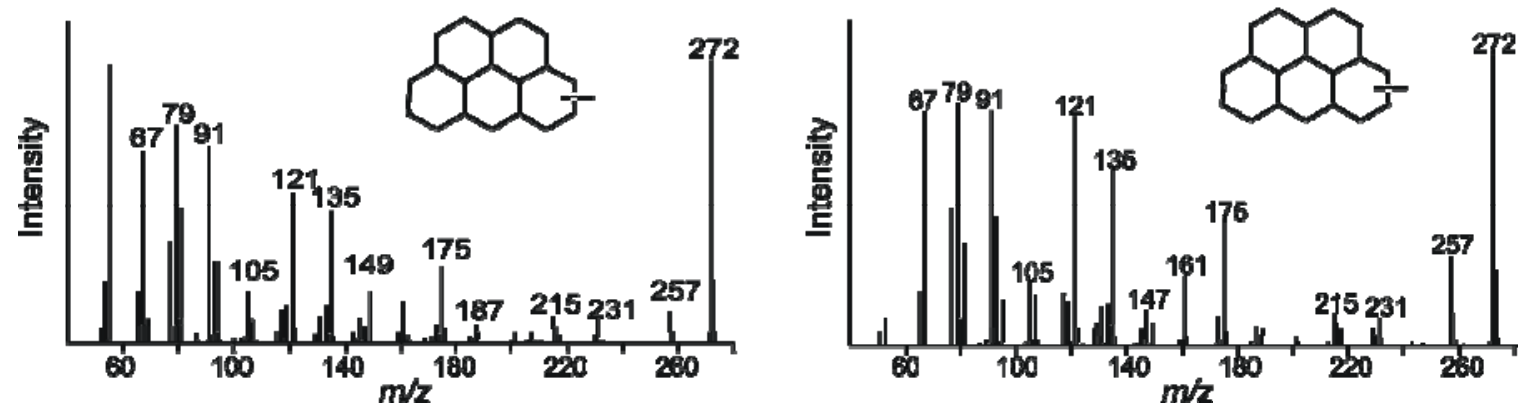

Figure 9. GC $\times$ GC-MS partial, summed mass chromatogram of the fragment ion $\mathrm{m} / \mathrm{z} 258+272$ of the s/u HC fraction of the Krist Formation sample DMSD showing the distribution of $\mathrm{C}_{19}$ and $\mathrm{C}_{20}$ pentacyclic compounds. Letters marking the order of mass spectra correspond to the peaks labels of the mass chromatogram. 

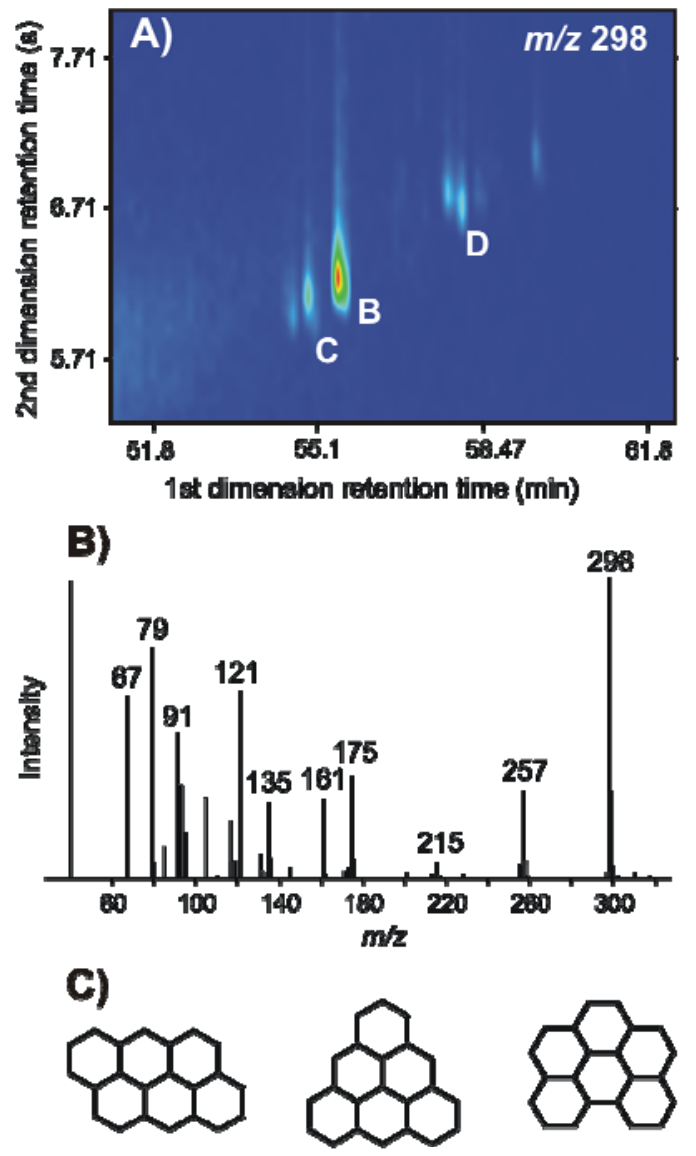

Figure 10. GC $\times$ GC-MS partial mass chromatogram of the fragment ion $m / z 298$ of the s/u HC fraction of the Krist Formation sample DMSD showing the distribution of $\mathrm{C}_{22}$ hexacyclic compounds. B) Mass spectra of peak B. C) Tentative structures of hexacyclic compound corresponding to peak $\mathrm{C}, \mathrm{B}$ and $\mathrm{D}$. 


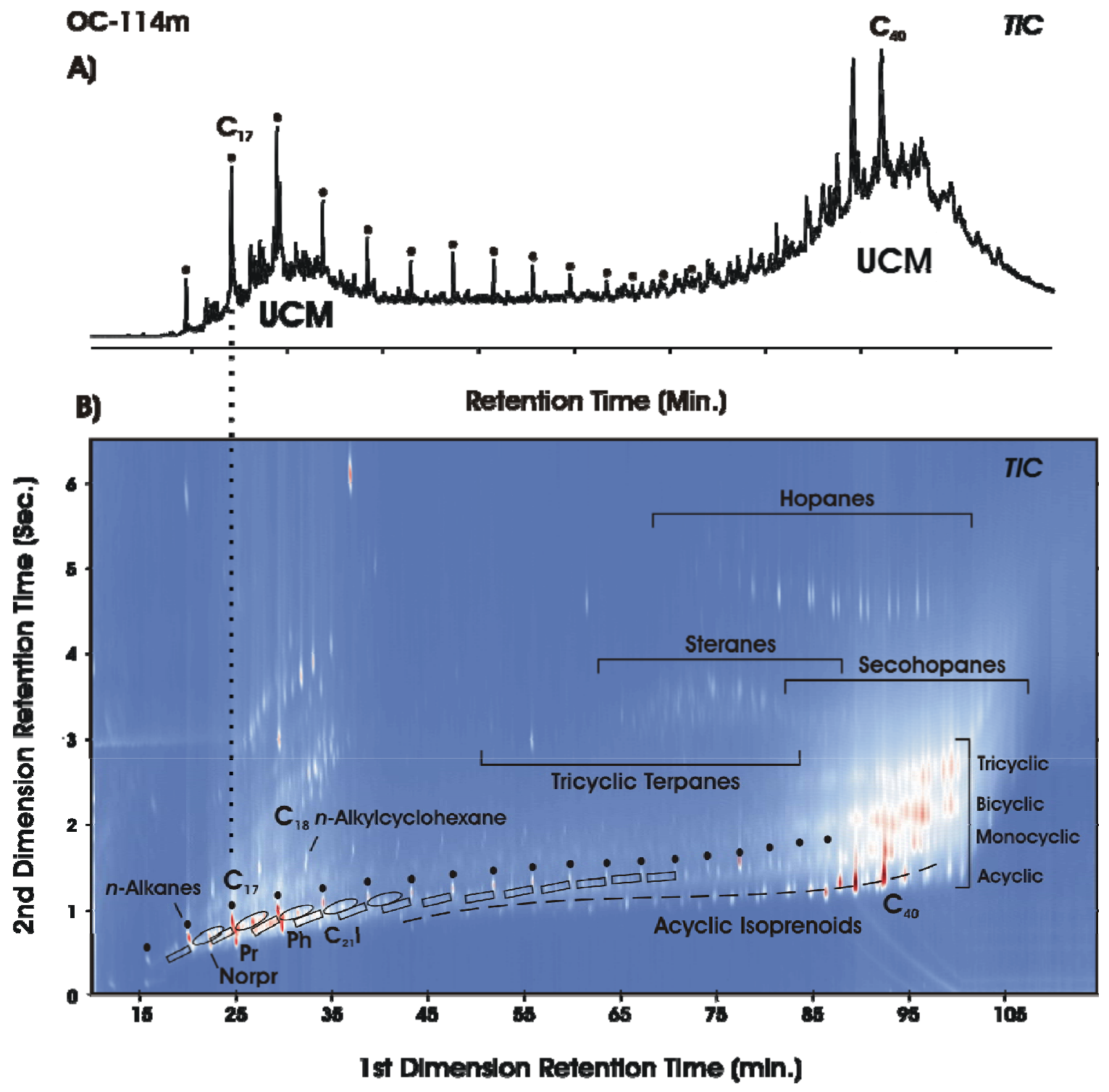

Figure 11. A) GC-MS TIC chromatogram of the s/u HC fraction of the bitumen from sample OC-114m (of the Hoyle Formation) containing a type I and II UCM. B) GC×GC-MS TIC chromatogram of the same sample with the labeled elution dimension of $n$-alkanes (black circles), mono-, bi-, tri-, tetra- (steranes), and pentacyclic (hopanes). Dotted line indicates irregular isoprenoids. Boxes encapsulate monomethylalkanes. Open ovals enclose monoethylalkanes. 

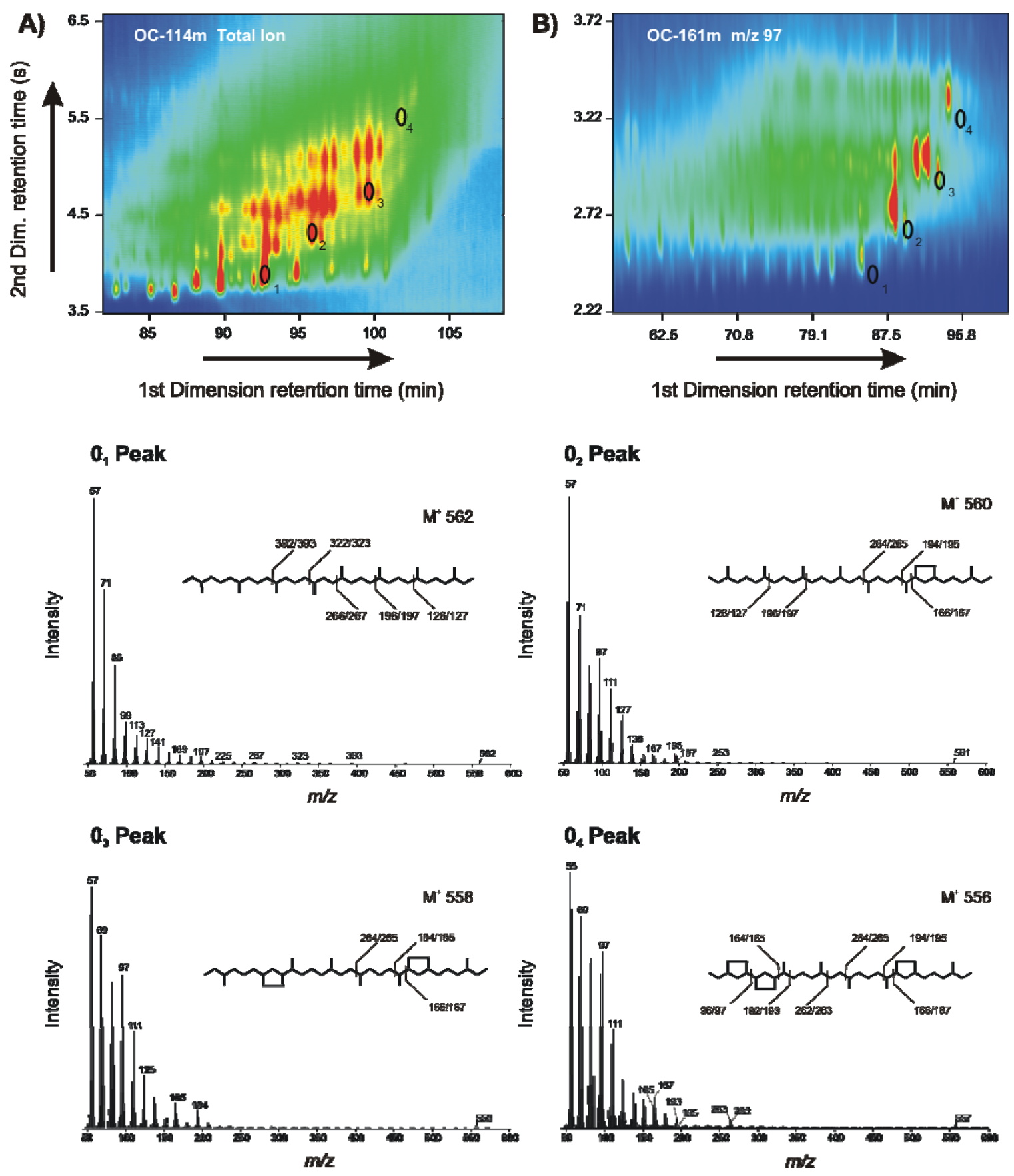

Figure 12. A) GC $\times$ GC-MS TIC chromatogram of sample OC-114m. $\mathrm{C}_{40}$ acyclic, mono-, bi-, and tricyclic biphytanes are labeled with black ovals. B) The $m / z 97 \mathrm{GC} \times \mathrm{GC}$ mass chromatogram of sample OC-161m coinjected with an archaeal lipid standard containing $\mathrm{C}_{40}$ acyclic, mono-, bi-, and tricyclic biphytanes. Below are mass spectra of peaks $0_{1}-0_{4}$ corresponding to the $\mathrm{C}_{40}$ mono-, bi-, and tricyclic biphytane in the OC-144m sample s/u HC fraction. 


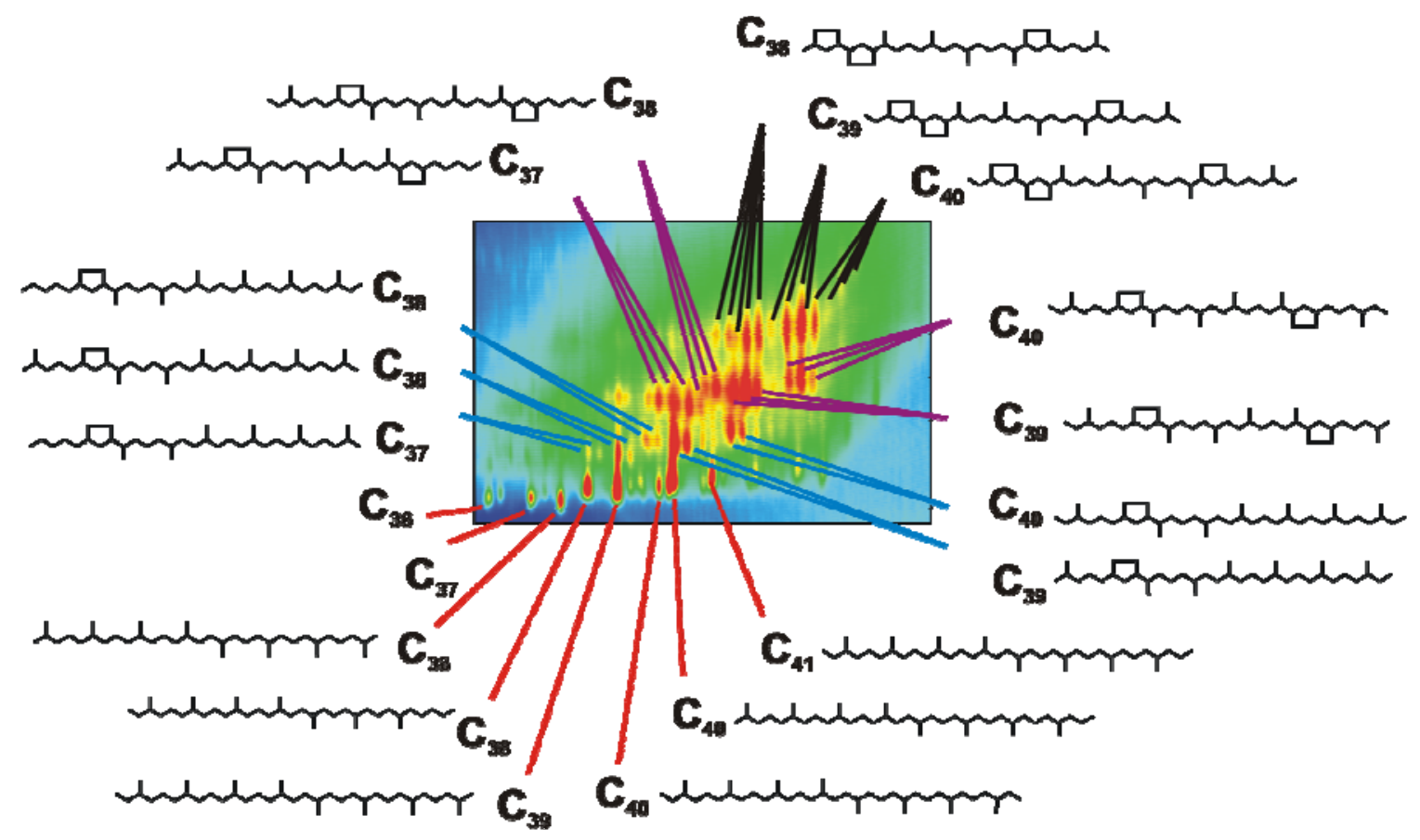

Figure 13. GC $\times$ GC-MS TIC chromatogram of the s/u HC fraction of Hoyle Formation sample OC-114m. Biphytane and acyclic derivatives of biphytane are labeled with red lines. The structures of mono-, bi-, and tricyclic biphytanes and their derivatives are marked by blue, purple, and black lines, respectively. Branched lines leading to the sample structures identify peaks in the chromatogram having the same mass spectra. 

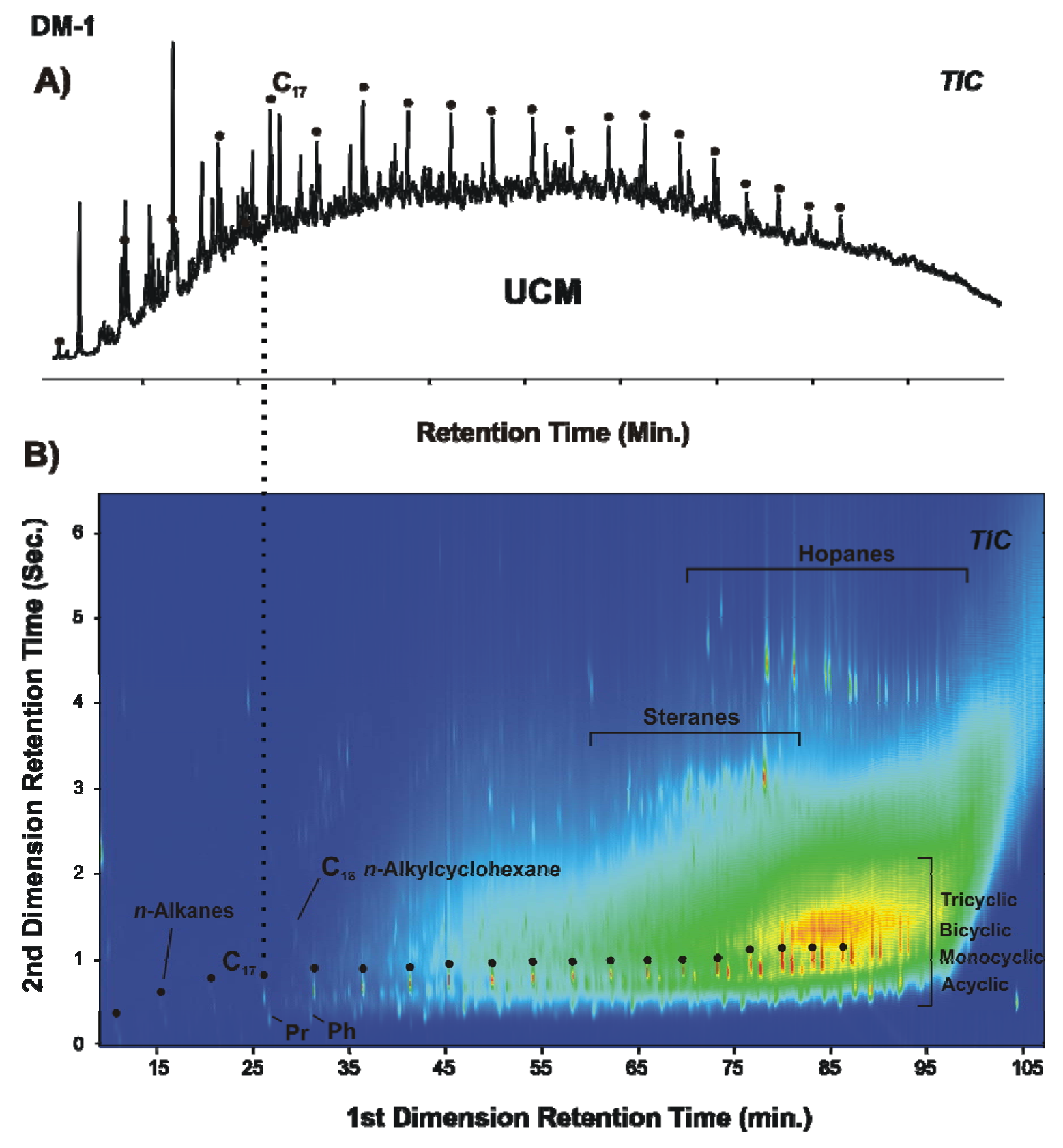

Figure 14. A) TIC chromatogram of the s/u HC fraction of the bitumen from sample DM-1 (of the Viapond Formation) containing a type III UCM. B) GC $\times$ GC-MS TIC chromatogram of the same sample with the labeled elution dimension of $n$-alkanes (black circles), mono-, bi-, tri-, tetra- (steranes), and pentacyclic (hopanes). 